\title{
Diagnostic accuracy of level 3 portable sleep tests versus level 1 polysomnography for sleep-disordered breathing: a systematic review and meta-analysis
}

\author{
Mohamed El Shayeb MD MSc, Leigh-Ann Topfer MLS, Tania Stafinski PhD, Lawrence Pawluk MD, \\ Devidas Menon PhD
}

\begin{abstract}
Background: Greater awareness of sleepdisordered breathing and rising obesity rates have fueled demand for sleep studies. Sleep testing using level 3 portable devices may expedite diagnosis and reduce the costs associated with level 1 in-laboratory polysomnography. We sought to assess the diagnostic accuracy of level 3 testing compared with level 1 testing and to identify the appropriate patient population for each test.
\end{abstract}

Methods: We conducted a systematic review and meta-analysis of comparative studies of level 3 versus level 1 sleep tests in adults with suspected sleep-disordered breathing. We searched 3 research databases and grey literature sources for studies that reported on diagnostic accuracy parameters or disease management after diagnosis. Two reviewers screened the search results, selected potentially relevant studies and extracted data. We used a bivariate mixed-effects binary regression model to estimate summary diagnostic accuracy parameters.
Results: We included 59 studies involving a total of 5026 evaluable patients (mostly patients suspected of having obstructive sleep apnea). Of these, 19 studies were included in the metaanalysis. The estimated area under the receiver operating characteristics curve was high, ranging between 0.85 and 0.99 across different levels of disease severity. Summary sensitivity ranged between 0.79 and 0.97 , and summary specificity ranged between 0.60 and 0.93 across different apnea-hypopnea cut-offs. We saw no significant difference in the clinical management parameters between patients who underwent either test to receive their diagnosis.

Interpretation: Level 3 portable devices showed good diagnostic performance compared with level 1 sleep tests in adult patients with a high pretest probability of moderate to severe obstructive sleep apnea and no unstable comorbidities. For patients suspected of having other types of sleep-disordered breathing or sleep disorders not related to breathing, level 1 testing remains the reference standard.
$\mathrm{U}$ ndiagnosed sleep-disordered breathing places a substantial burden on patients, families, health care systems and society. ${ }^{1}$ Sleep fragmentation and recurrent hypoxemia cause daytime sleepiness and impaired concentration, which increase the risk of motor vehicle collisions and occupational accidents. ${ }^{2-7}$ In addition, sleep-disordered breathing is associated with hypertension, stroke, cardiovascular disease, obesity and type 2 diabetes, ${ }^{8-12}$ all of which involve greater use of health care resources. ${ }^{13-17}$

Obstructive sleep apnea is the most common type of sleep-disordered breathing. Narrowing of the upper airway during inspiration results in episodes of apnea (breathing cessation for at least 10 seconds), hypopnea (reduced airflow), oxygen desaturation and arousal from sleep due to respiratory effort. ${ }^{18}$ Clinical signs and symptoms include snoring, reports of nocturnal apnea, gasping or choking witnessed by a partner, daytime sleepiness, morning headaches and inability to concentrate. Patients with obesity or cardiovascular disease are at increased risk. ${ }^{19}$

The severity of obstructive sleep apnea is usually graded using the apnea-hypopnea index (the mean number of apneas and hypopneas per hour of sleep) as follows: mild (5-14), moderate (15$29)$ and severe $(\geq 30) \cdot{ }^{18,20}$

Other, less common types of sleep-disordered breathing include upper airway resistance syndrome, obesity hyperventilation syndrome, central sleep apnea, and nocturnal hypoventilation/ hypoxemia secondary to cardiopulmonary or neuromuscular disease. It is not uncommon for patients to have more than 1 type of sleepdisordered breathing.

Estimates of the prevalence of sleep-disordered breathing vary depending on the population (e.g., by sex, age and comorbidities). ${ }^{21}$ According to the
Competing interests: None declared.

This article has been peer reviewed.

Correspondence to: Mohamed El Shayeb, elshayebm@ualberta.ca

CMAJ 2014. DOI:10.1503 /cmaj.130952 
Wisconsin Sleep Cohort Study, values in American adults (aged 30-60 yr) are 24\% for men and $9 \%$ for women. ${ }^{1}$ A Canadian survey found a selfreported prevalence of sleep apnea of 3\% among adults more than 18 years of age, and 5\% among those more than 45 years of age..$^{22}$ As the population ages and rates of obesity increase, the prevalence of sleep-disordered breathing is climbing. ${ }^{1,192324}$ Given its clinical implications, accurate diagnosis and treatment of the condition are critical.

Level 1 sleep testing, or polysomnography, requires an overnight stay in a sleep laboratory with a technician in attendance. It captures a minimum of 7 channels of data (but typically $\geq 16$ ), including respiratory, cardiovascular and neurologic parameters, to produce a comprehensive picture of sleep architecture. Level 1 is considered the reference standard for diagnosing all types of sleep-disordered breathing and sleep disorders. ${ }^{19,25-27}$ However, limited facilities and the growing demand for sleep studies have resulted in long wait times. ${ }^{28}$ Level 2 sleep testing uses level 1 equipment, but is performed without a technician in attendance.

Level 3 testing uses portable monitors that allow sleep studies to be done at the patient's home or elsewhere. This option was introduced as a more accessible and less expensive alternative to in-laboratory polysomnography. Level 3 devices record at least 3 channels of data (e.g., oximetry, airflow, respiratory effort). Unlike level 1 , level 3 testing cannot measure the duration of sleep, the number of arousals or sleep stages, nor can it detect nonrespiratory sleep disorders. ${ }^{27,29}$ Level 4 devices are also portable, but they capture less data - usually only 1 or 2 channels..$^{27,30}$

We conducted a systematic review and metaanalysis to compare the diagnostic accuracy of the widely used level 3 portable monitors to inlaboratory polysomnography, and to determine the subpopulations of patients whose conditions might be most appropriately diagnosed with each test.

\section{Methods}

\section{Literature search}

We performed a comprehensive literature search of PubMed (MEDLINE and non-MEDLINE sources), the Cochrane Library and Embase for studies that compared level 3 to level 1 tests for the diagnosis of sleep-disordered breathing in adults (Appendix 1, available at www.cmaj.ca /lookup/suppl/doi:10.1503/cmaj.130952/-/DC1). We limited our search to English-language studies from 2007 to March 2012, with monthly updates from PubMed until March 2013. We also included studies from a previous systematic review prepared by our research unit, which cov- ered the literature from 2004 to 2009. Consequently, this review covers the literature from 2004 to March 2013. We determined our date limit based on several previous Canadian and American assessments that examined the earlier literature. $^{31-40}$

\section{Study selection}

Two reviewers independently screened titles and abstracts to identify possible studies for inclusion. All studies comparing level 3 with level 1 sleep tests involving adults were included if they reported on either diagnostic accuracy parameters or management after testing (Appendix 2, available at www.cmaj.ca/lookup/suppl/doi:10 .1503/cmaj.130952/-/DC1). We followed PICOS (Patients, Intervention, Comparator, Outcomes and Study design) criteria to include or exclude studies. We assessed reviewer agreement using the $\kappa$ statistic.

\section{Data extraction}

Two reviewers independently extracted data from included studies using a standard form. Our diagnostic accuracy parameters were sensitivity, specificity, area under the receiver operating characteristic (ROC) curve, and positive and negative likelihood ratios. We extracted safety data and technical failures from all of the studies that reported these parameters. Our clinical management parameters were acceptance of continuous positive airway pressure treatment, treatment adherence, mechanical estimates of residual apnea-hypopnea index, mean machine pressure difference between patients whose diagnoses were made with the 2 different tests, quality of life and functional status as measured by clinical sleepiness questionnaires (usually the Epworth Sleepiness Scale).

Disagreements were discussed and resolved between the reviewers. No third-party adjudication was needed.

\section{Quality assessment}

We used the Quality Assessment of Diagnostic Accuracy Studies-2 (QUADAS-2) tool, which assesses bias (internal validity) and applicability (external validity) in multiple domains: flow and timing, reference-standard test, index test and patient selection. ${ }^{41,42}$

\section{Statistical analysis}

We pooled patient characteristics (age, body mass index [BMI] and score on the Epworth Sleepiness Scale) to obtain weighted averages. We extracted and grouped comorbidities. We presented technical failures and safety data as frequencies and proportions. 
Because studies reported level 3 test performance at different apnea-hypopnea index severity levels, we examined diagnostic accuracy parameters in all studies to determine the overall ranges. We examined patterns at different severity levels in studies that reported multiple index cut-offs.

We performed a meta-analysis using a bivariate mixed-effects binary regression model. The model estimates the amount of between-study variation in sensitivity and specificity, as well as the degree of correlation between sensitivity and specificity through random effects, and uses the logit sensitivity and specificity to draw the summary ROC curves. This model requires the primary parameters of true-positive, false-positive, true-negative and false-negative. We included studies if they reported the parameters required for the model. If such parameters were not reported, we calculated them from the data provided, where possible. We estimated summary diagnostic accuracy parameters. ${ }^{43-45}$ We assessed overall heterogeneity using the $Q$ statistic. When heterogeneity was significant, we quantified it using the $I^{2}$ statistic. We estimated the summary ROC curves at different apnea-hypopnea severity levels. We performed all analyses using Stata SE version 12.

We conducted a subgroup sensitivity analysis to identify changes in diagnostic accuracy when studies that included only patients with comorbidities were removed from the analysis.

\section{Results}

We included 59 comparative studies (15 abstracts, 44 full-text articles) involving 5044 patients (5026 of whom were evaluable) in our analysis (Figure 1). The $\kappa$ statistic showed reviewer agreement $(0.86)$.

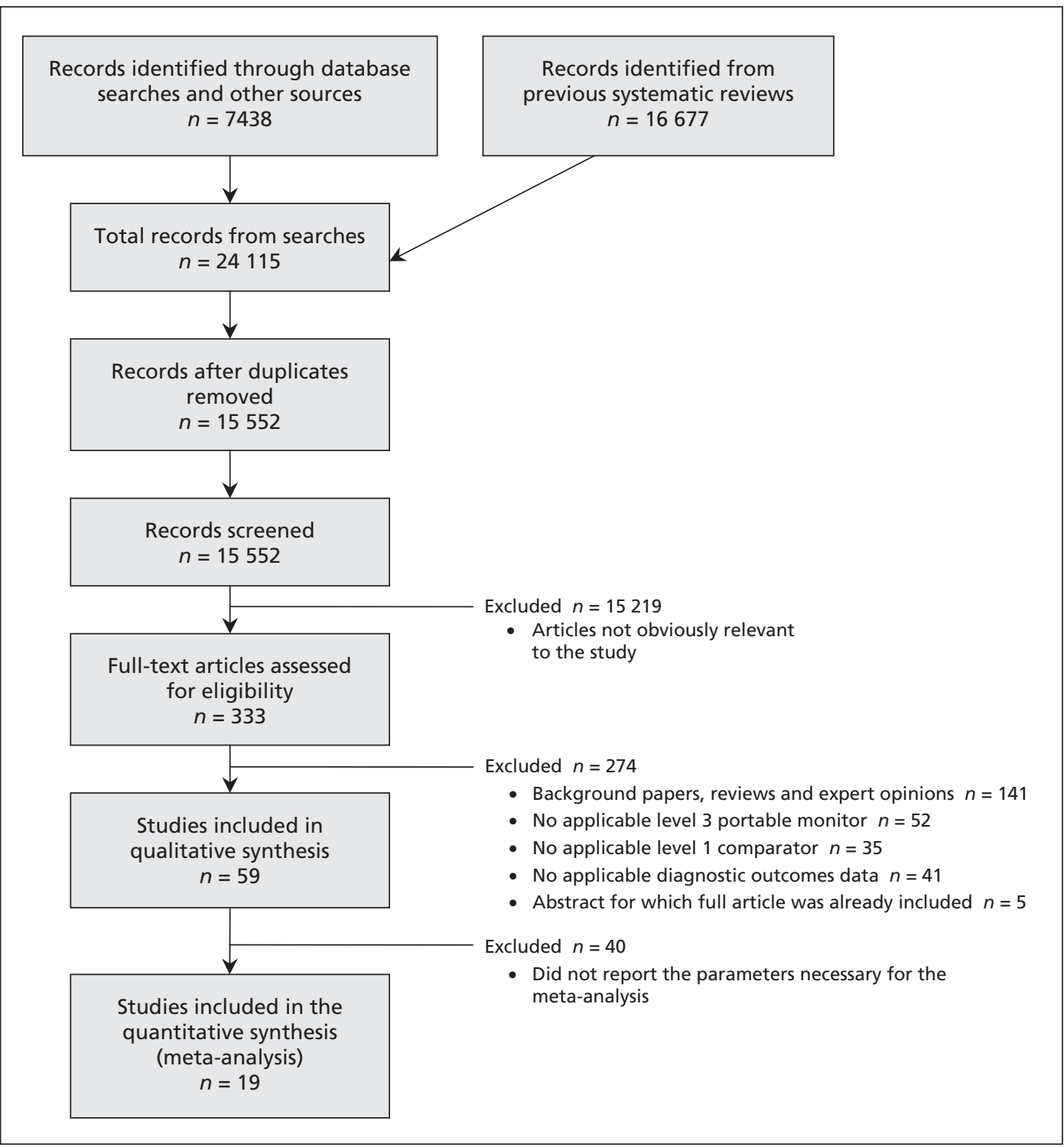

Figure 1: Selection of studies for inclusion in the review and meta-analysis. 
We classified the included studies as "combination" studies (10 studies involving 572 evaluable patients, in which the patients underwent simultaneous in-laboratory level 3 and level 1 tests, followed by an at-home level 3 test), "simultaneous" studies (20 studies involving 1152 evaluable patients, in which the patients underwent simultaneous in-laboratory level 3 and level 1 tests) and "separate" studies (29 studies involving 3302 evaluable patients, in which an at-home level 3 test and an inlaboratory level 1 test were conducted, either with the same patients or on 2 different arms) (Table 1). ${ }^{46-104}$

\section{Patient characteristics}

The included studies recruited patients with suspected obstructive sleep apnea (Appendix 3, available at www.cmaj.ca/lookup/suppl/doi:10 $.1503 / \mathrm{cmaj} .130952 /-/ D C 1)$. Patients were referred for sleep testing after a pretest assessment that included sleep questionnaires, history and clinical examination.

When we pooled participant characteristics from all studies, patients had a mean age of 50.8 years, a mean score of 11.6 on the Epworth Sleepiness Scale and a mean BMI of 30.4. The ratio of male to female patients was 2.9 to 1 . A total of 1382 comorbidities were reported, with cardiovascular conditions the most common (1080 patients, $78.1 \%$ of total comorbidities). Hypertension was the most frequently reported cardiovascular condition (574 patients), followed by stable chronic heart disease (142 patients) and coronary artery disease (113 patients). Respiratory comorbidities were limited to a single patient with asthma and 9 patients with chronic obstructive pulmonary disease $(0.7 \%$ of total comorbidities).

\section{Study characteristics}

The 4 channels measured in all of the studies were nasal airflow, thoracoabdominal movement, oxygen saturation and body position.

Two studies reported adverse events with inlaboratory level 3 tests ( 1 hypertensive crisis, 1 pacemaker interference) ${ }^{46,52}$ One study reported sensor irritation in 27 patients. ${ }^{46}$

Technical failures affected $0.44 \%$ of patients who underwent level 1 tests, $1.30 \%$ of patients who underwent in-laboratory level 3 tests and $10.25 \%$ of patients who underwent level 3 tests at home (Appendix 4, available at www.cmaj.ca /lookup/suppl/doi:10.1503/cmaj.130952/-/DC1).

\section{Diagnostic accuracy of sleep tests}

Among all included studies, the area under the ROC curves for at-home ( 6 studies) and in- laboratory (7 studies) testing showed values of 0.90 or greater at all apnea-hypopnea index cutoffs, with the exception of 2 studies that reported values of 0.79 and 0.86 at an apnea-hypopnea index of moderate or severe ( $\geq 15$ events/h) at home, and 2 studies that reported values ranging from 0.87 to 0.89 at moderate or severe cut-offs ( $\geq 15, \geq 20$ and $\geq 30$ events/h) in laboratory (Appendix 5, available at www.cmaj.ca/lookup /suppl/doi:10.1503/cmaj.130952/-/DC1).

In studies reporting multiple cut-offs, with increasing disease severity, 7 of 10 at-home studies showed a decline in sensitivity and an increase in specificity, and 2 of the studies showed an increase in area under the ROC curve. ${ }^{46-48,52,55,81,88,89,98,104}$ In addition, 7 of 14 inlaboratory studies showed a decline in sensitivity and an increase in specificity, and 2 studies showed an increase in area under the ROC curve. ${ }^{47,48,51,52,58,61-63,65-67,69-71}$

We found no significant difference in baseline characteristics between the 2 groups of patients in all 8 studies that reported disease management after the diagnosis by either test. None of the studies found significant differences in disease management parameters. ${ }^{77-79,92,93,99,102,103}$

In most of the studies, patients underwent both level 1 and level 3 tests to avoid the risk of internal bias due to differences between study groups. In all of the simultaneous studies, level 3 tests were scored manually by the same technician who scored the level 1 test, which may have resulted in observer bias. In contrast, most of the studies reported blinding the interpreters of level 3 tests to the level 1 test results, mitigating the risk of observer bias.

Most of the studies adequately described the tests, number of patients, recruitment methods and dropouts. Fifteen studies (only available as abstracts) had incomplete reporting of 1 or more elements (Table 2).

Most studies recruited patients suspected of having simple obstructive sleep apnea without comorbidities or with stable cardiovascular comorbidities. None of the studies included patients with other forms of sleep-disordered breathing (Table 2).

\section{Results of the meta-analysis}

We identified 19 studies reporting the parameters needed for our meta-analysis (Table 3). Among these studies, we found moderate to high heterogeneity at a mild apnea-hypopnea index cut-off in laboratory ( $\geq 5$ events/h) and at home ( $\geq 10$ events/h), and at a moderate cut-off for both settings $\left(\geq 15\right.$ events/h) $\left(I^{2} 53 \%-85 \%\right){ }^{105}$ Overall, diagnostic accuracy improved as disease severity increased (Figures 2 and 3). 


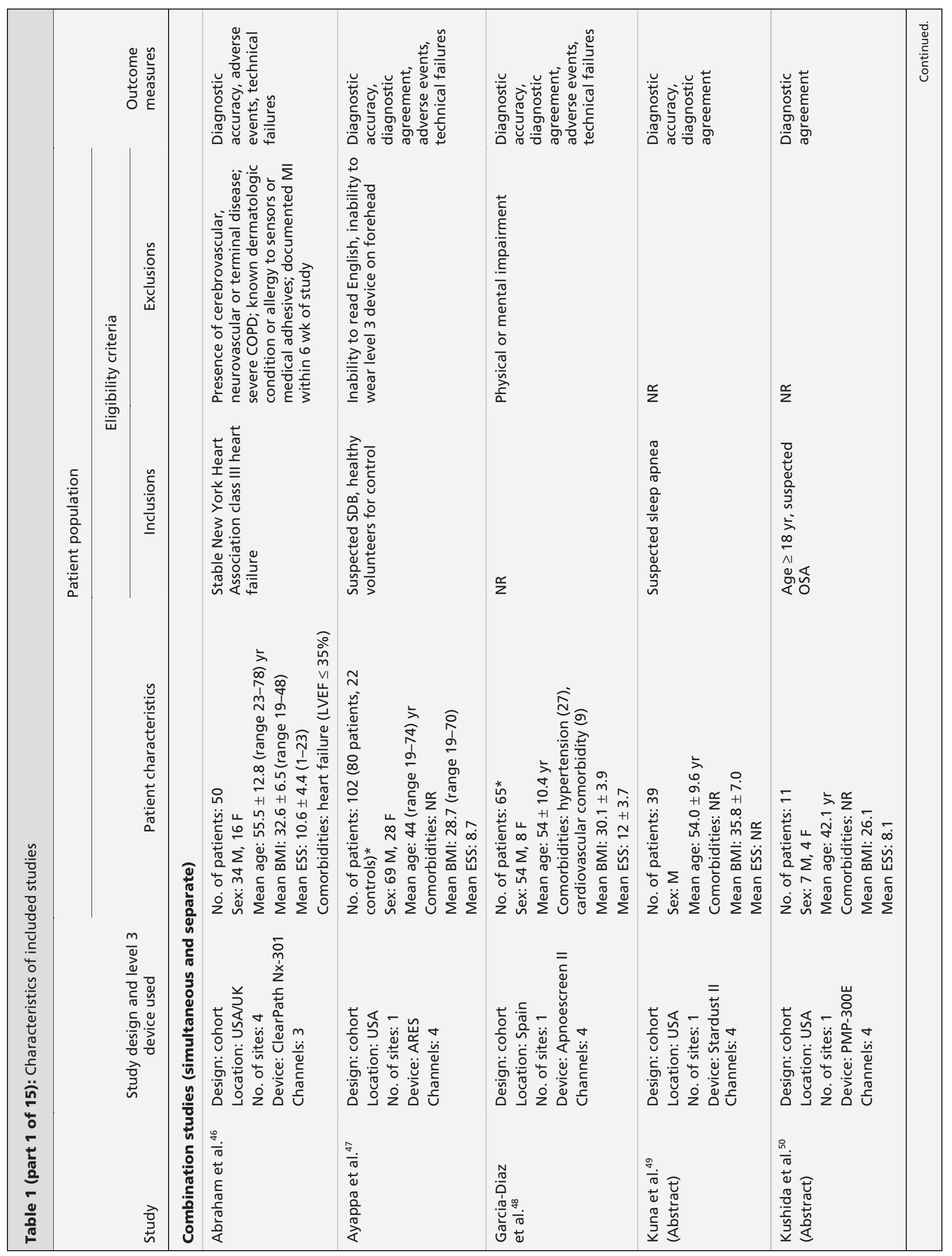




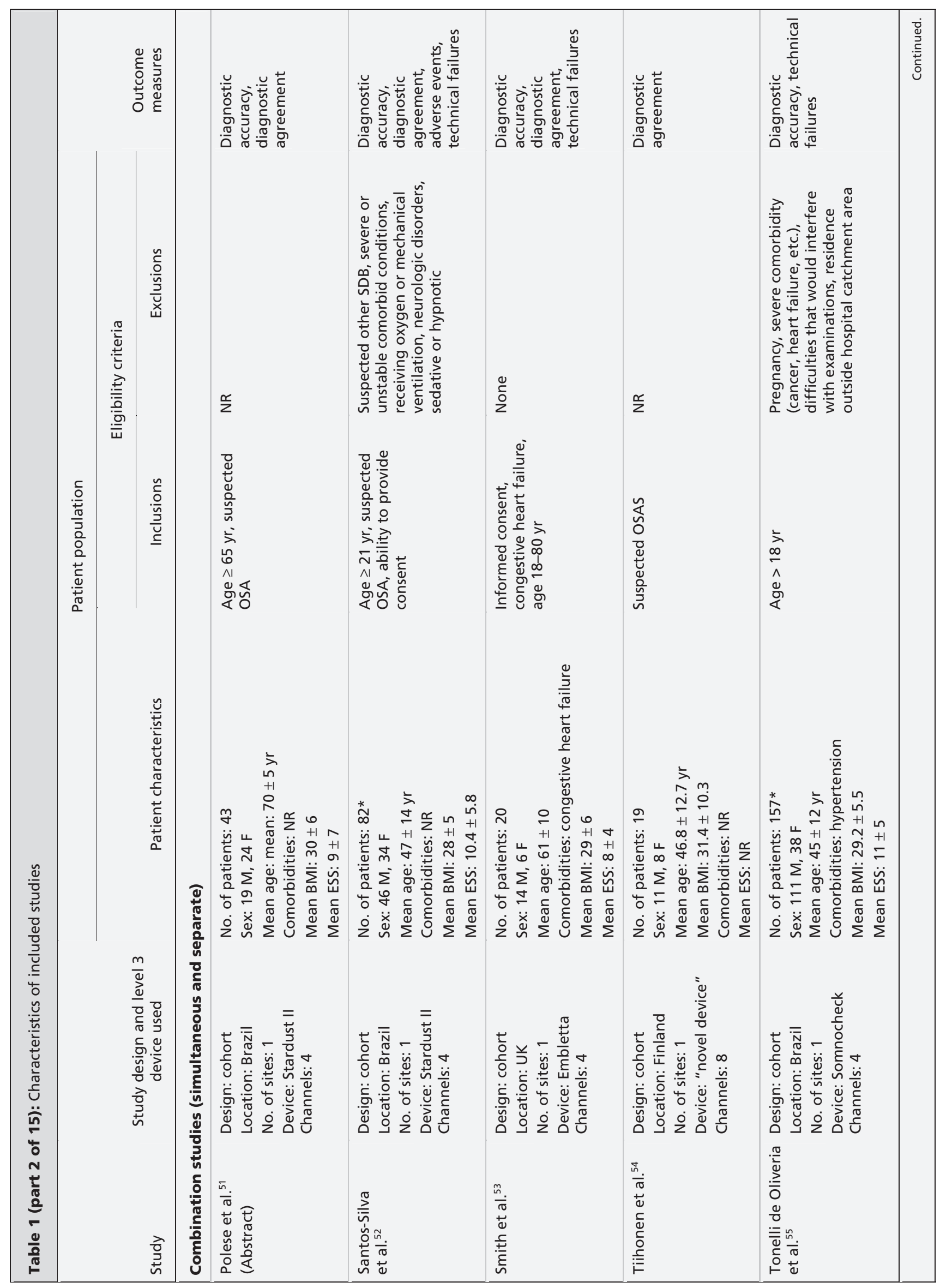




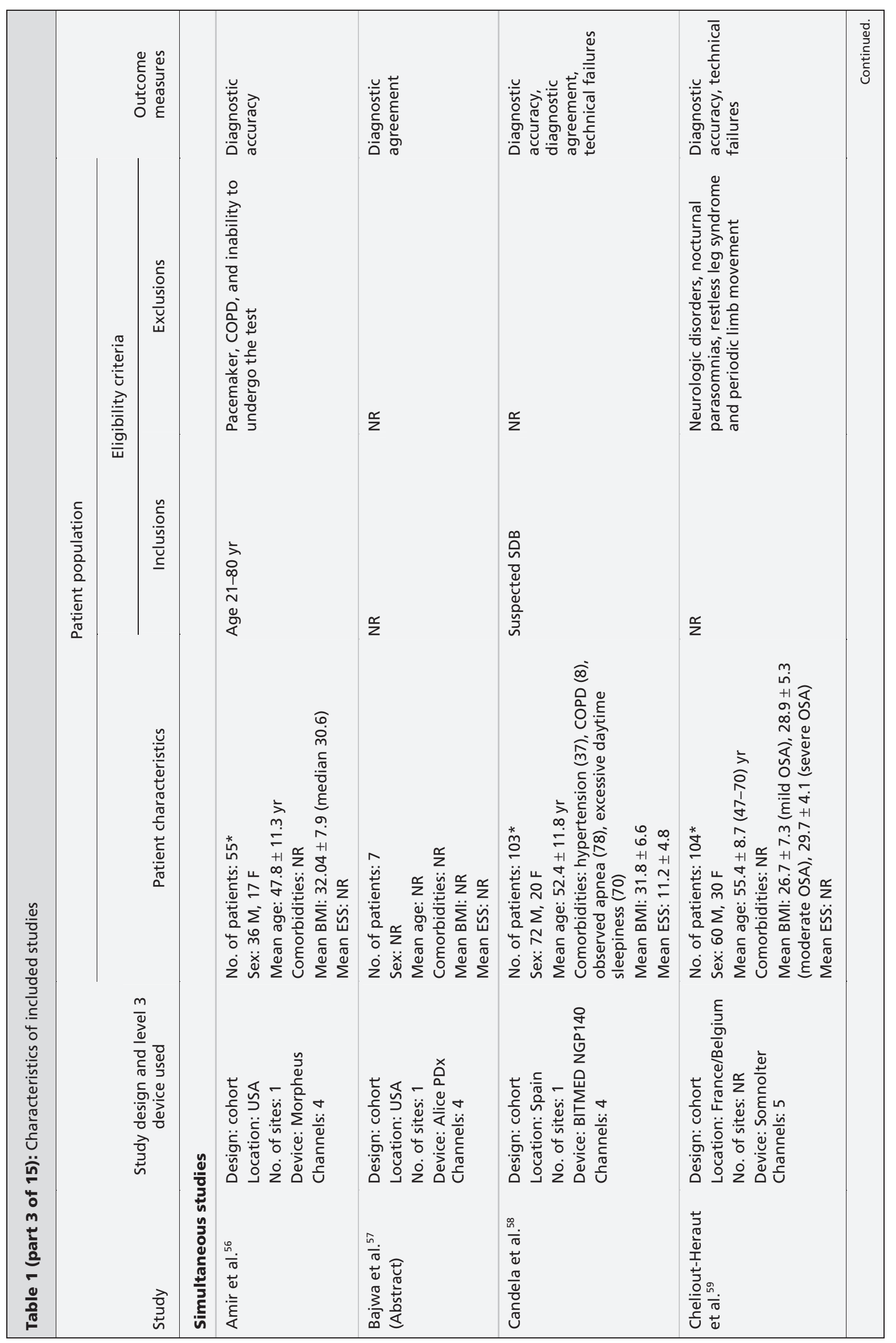




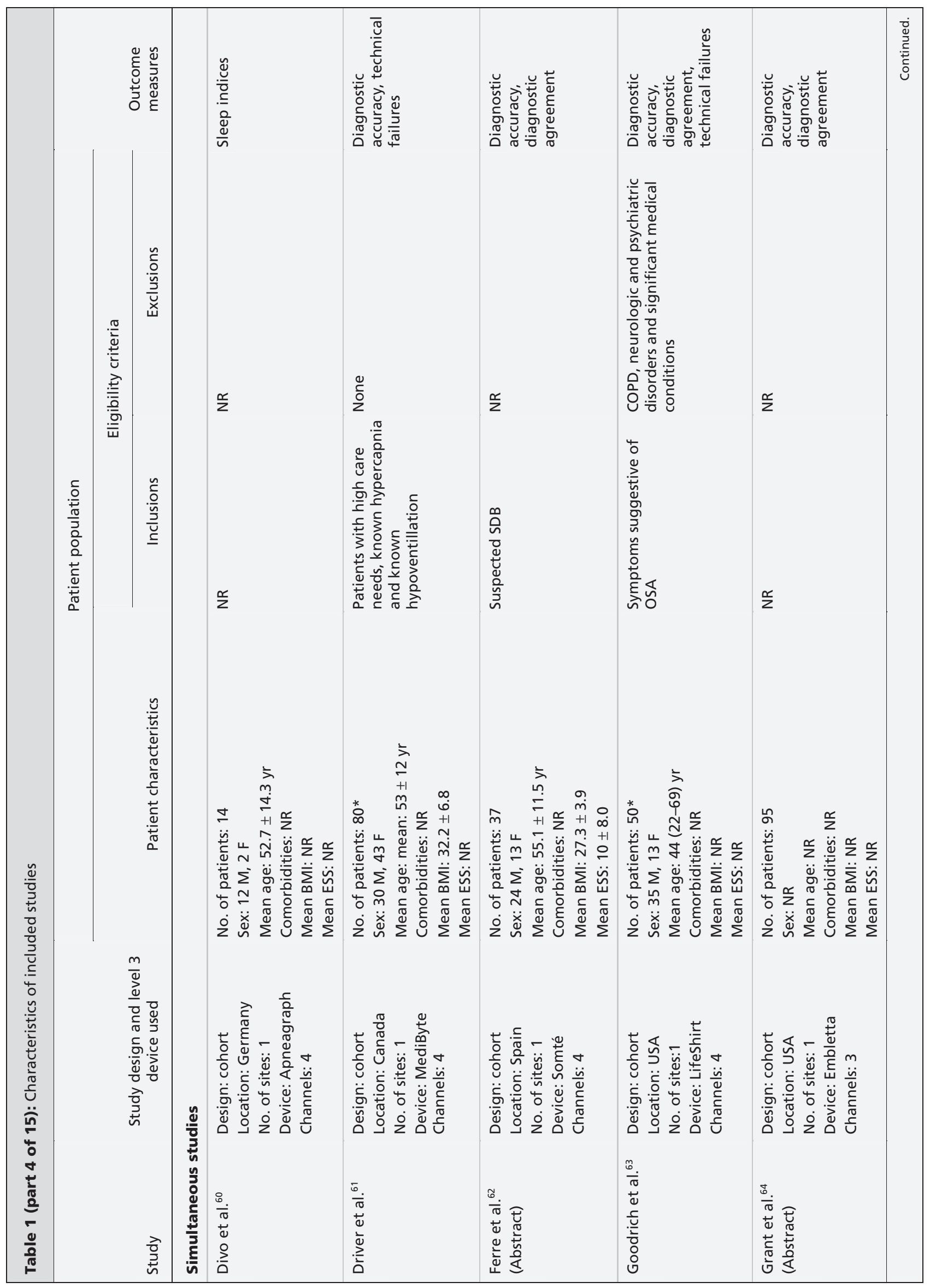




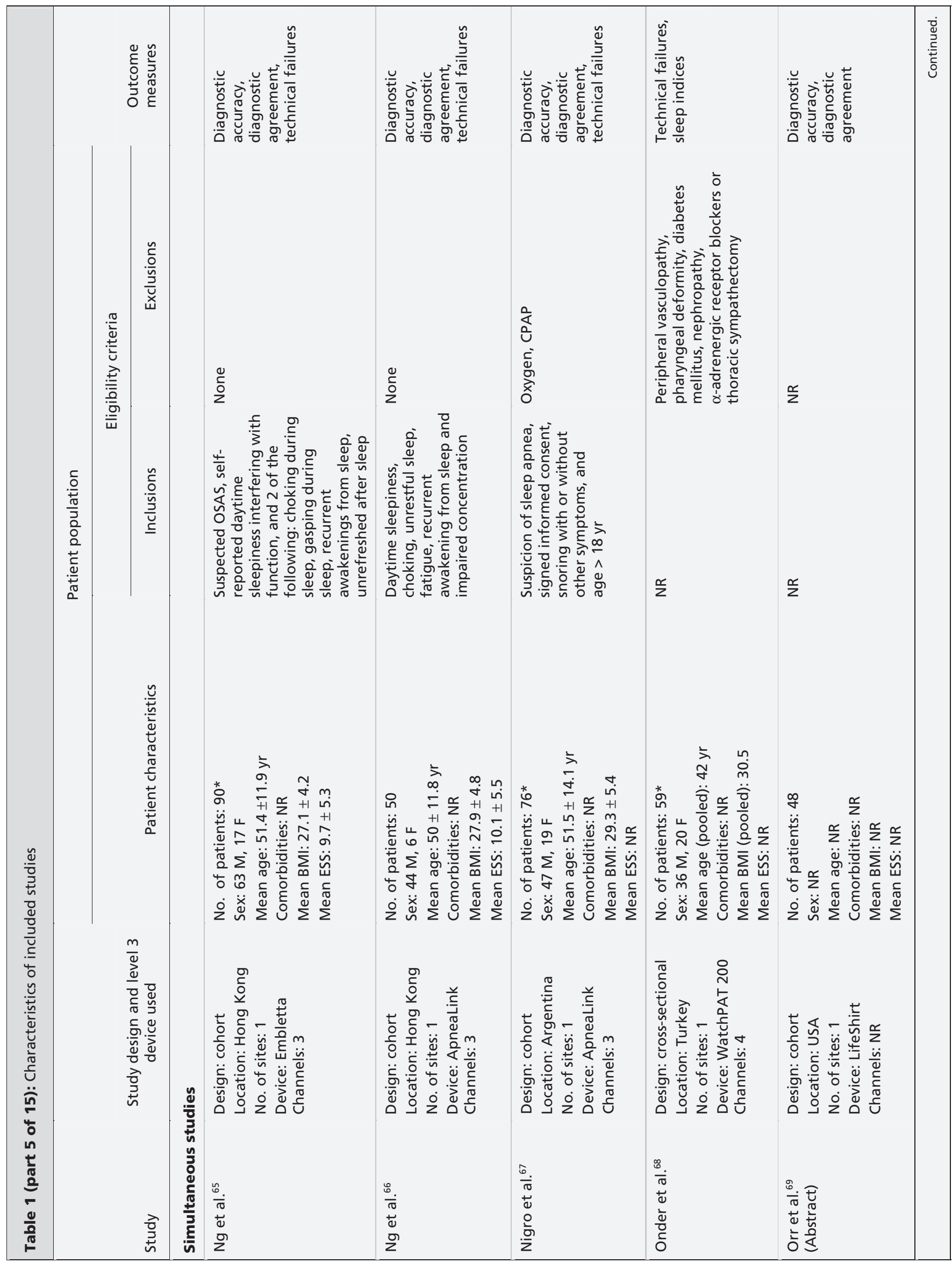




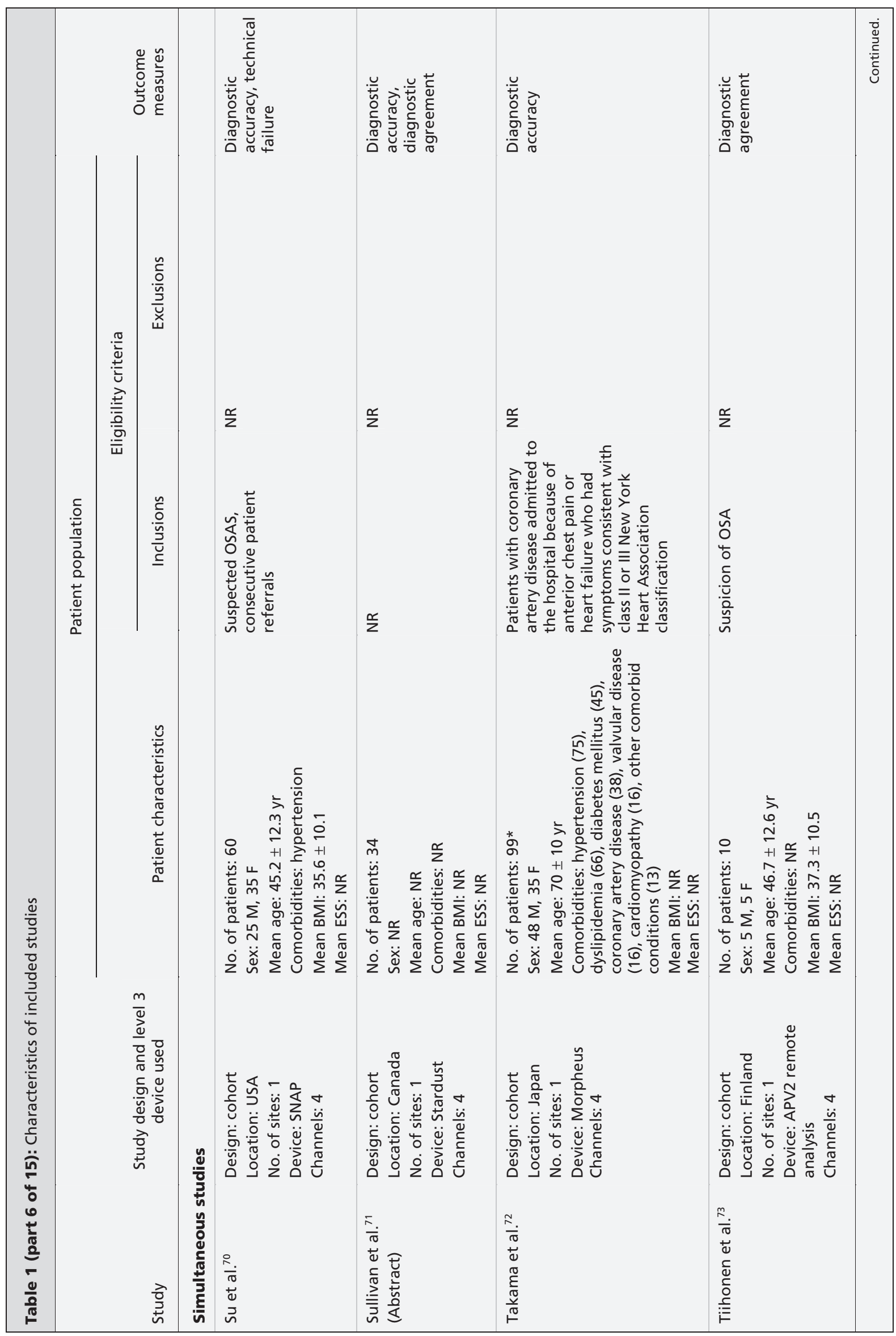




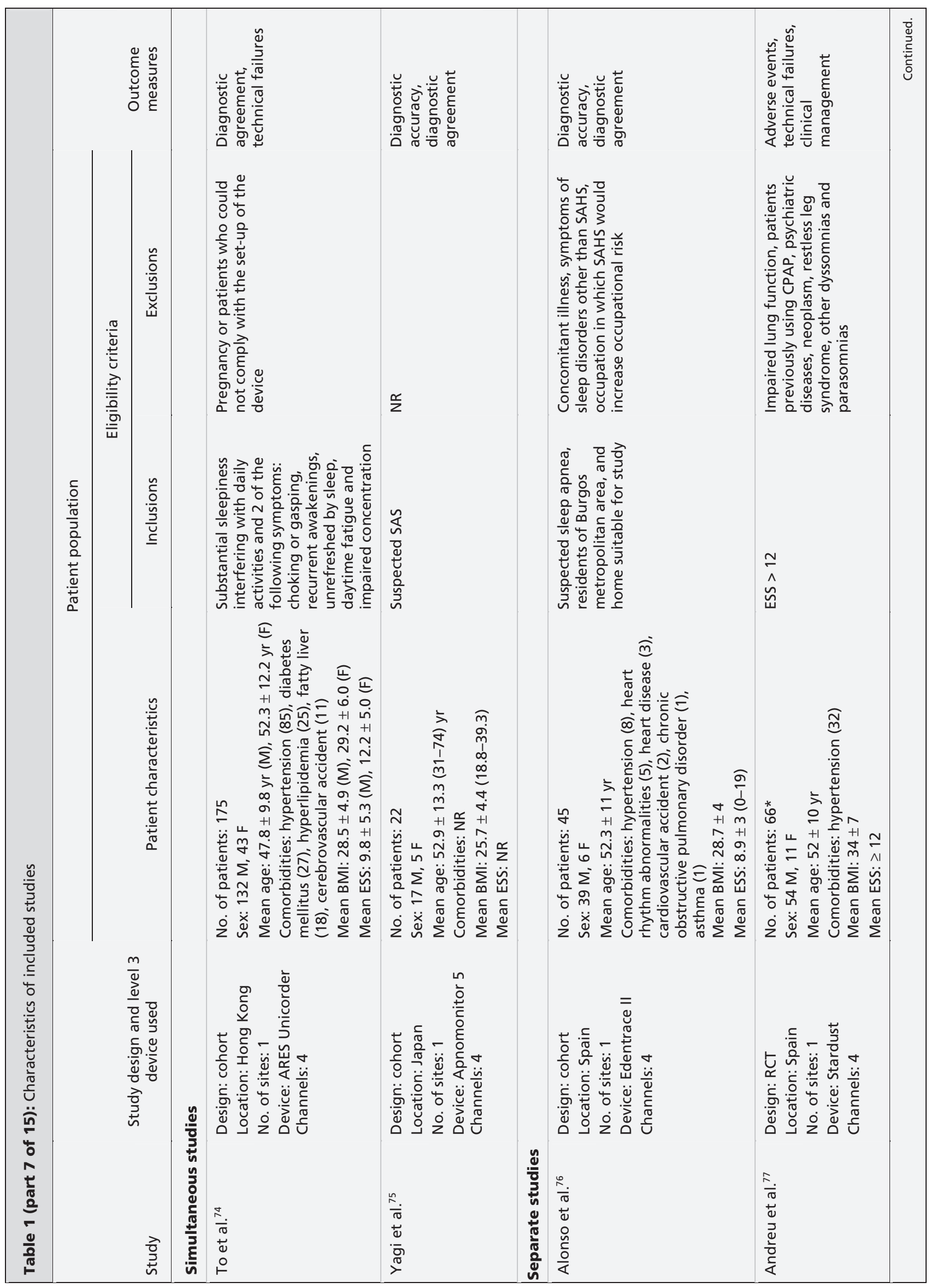




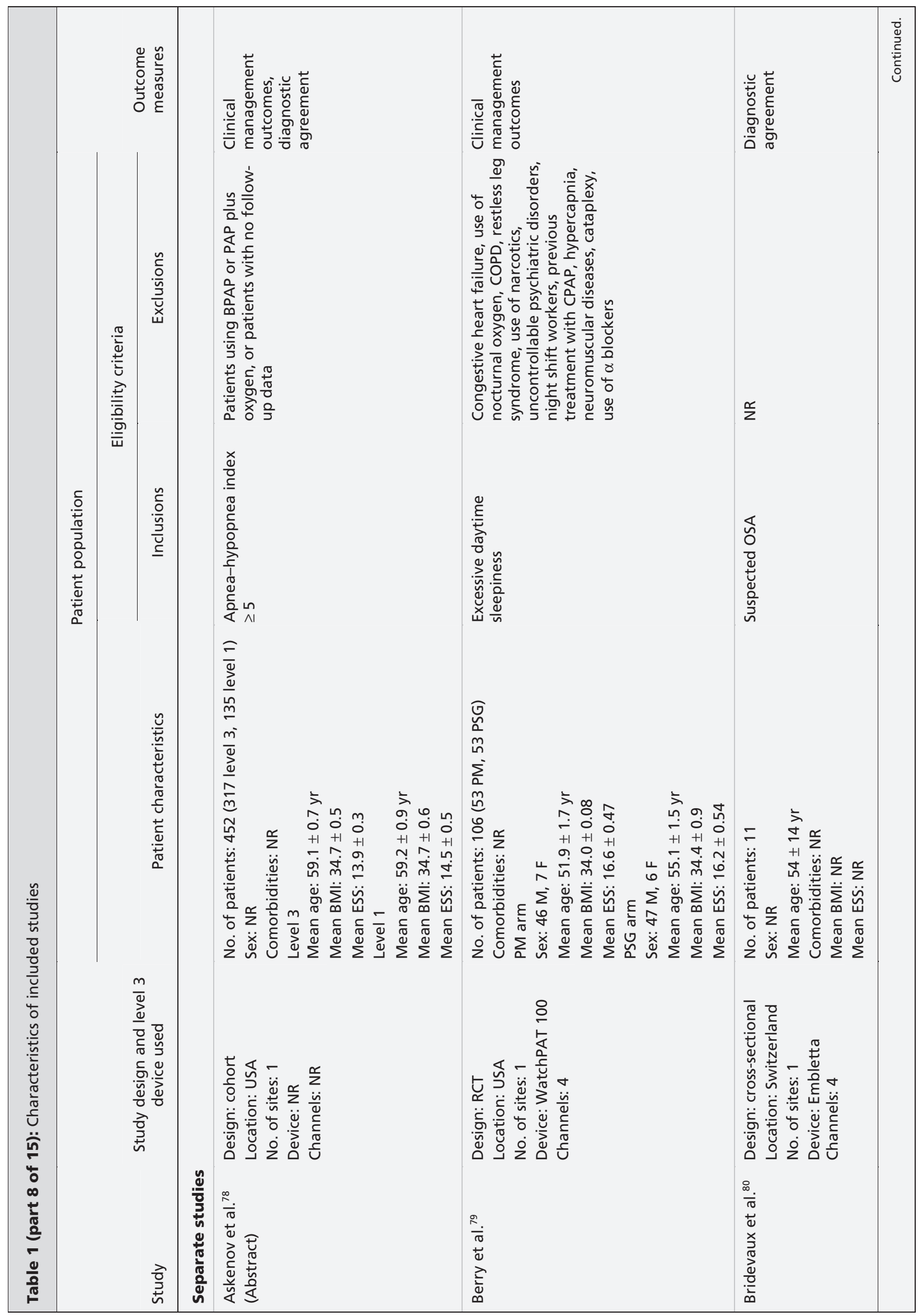




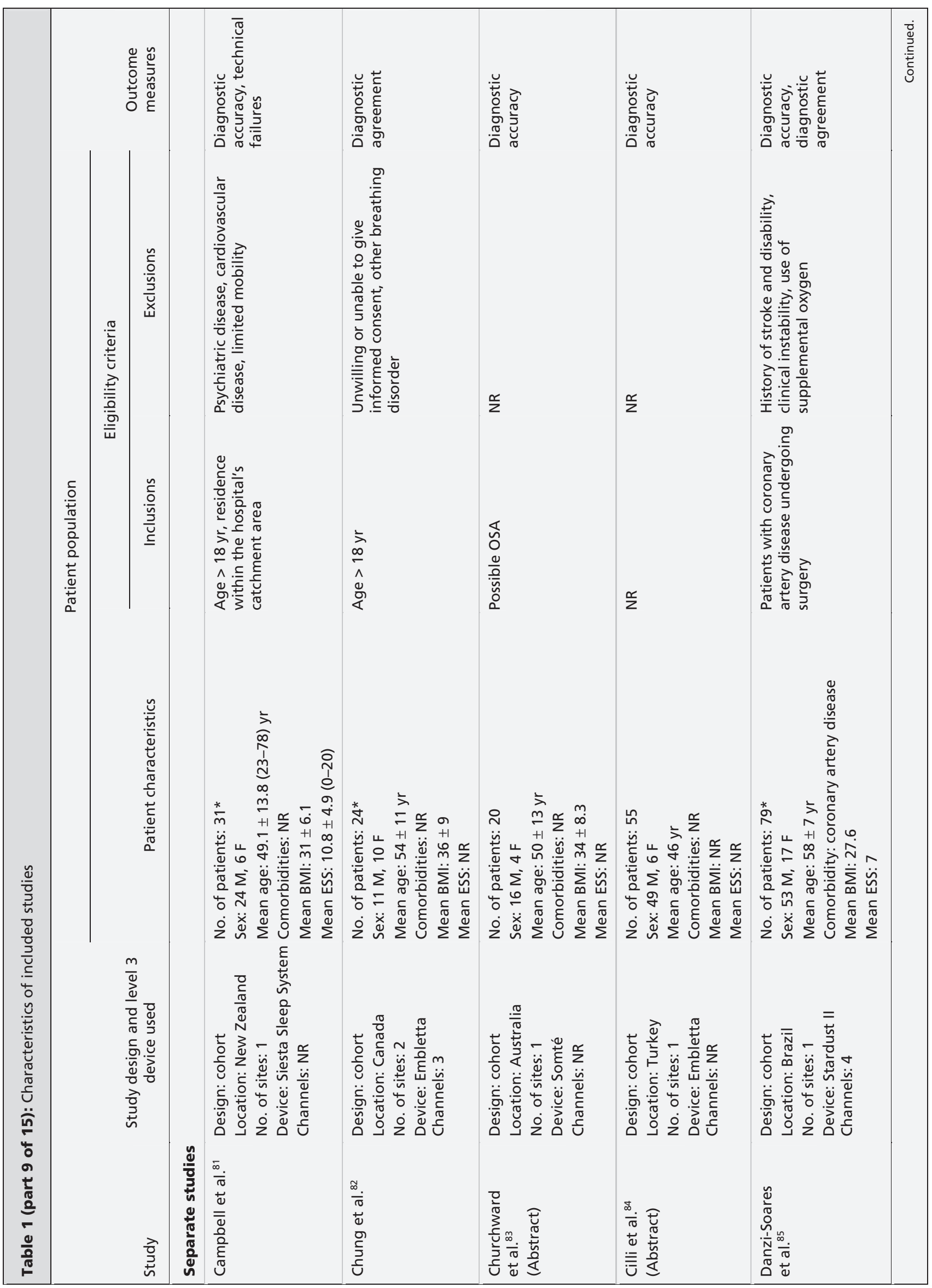




\section{RESEARCH}

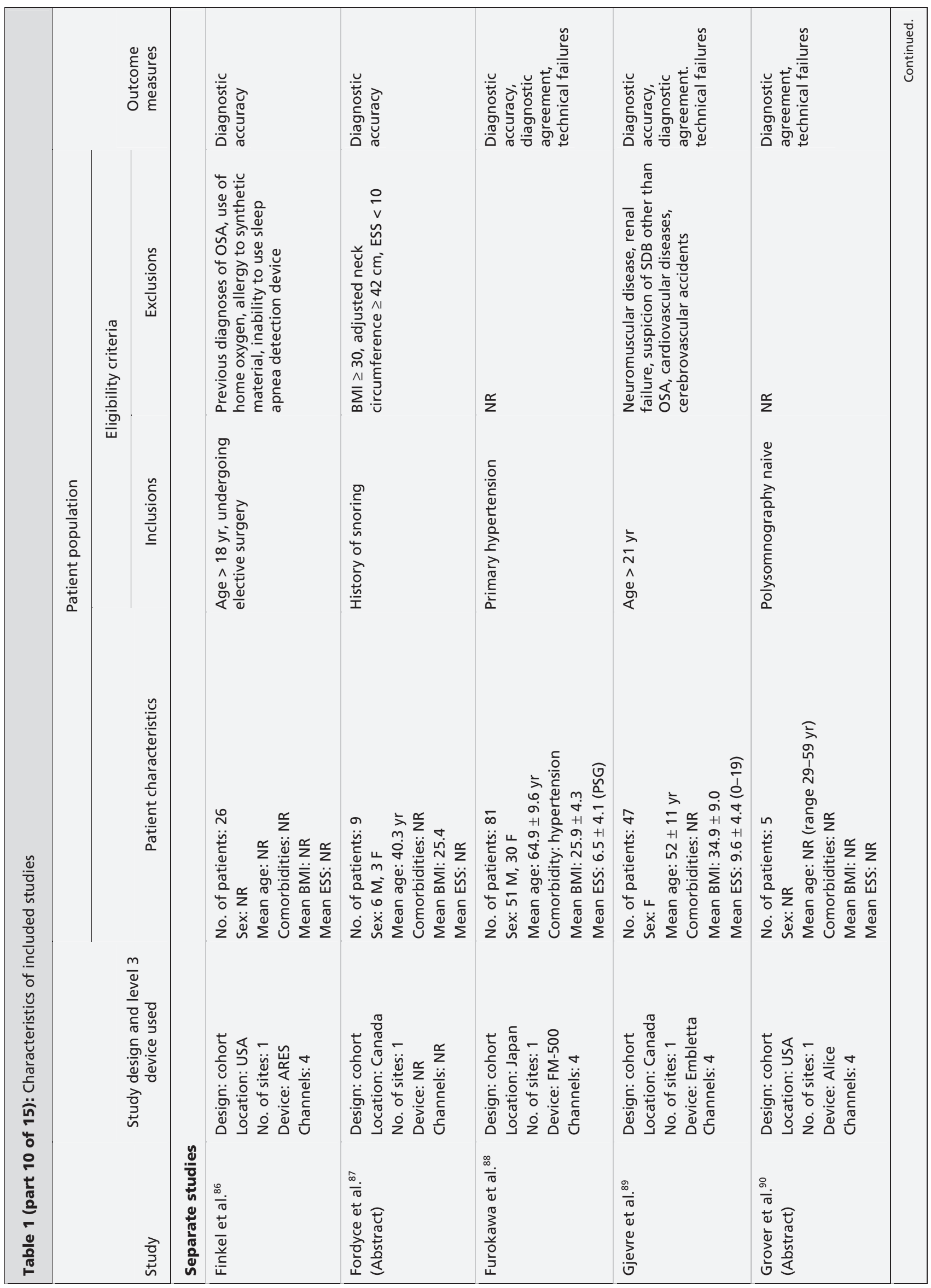




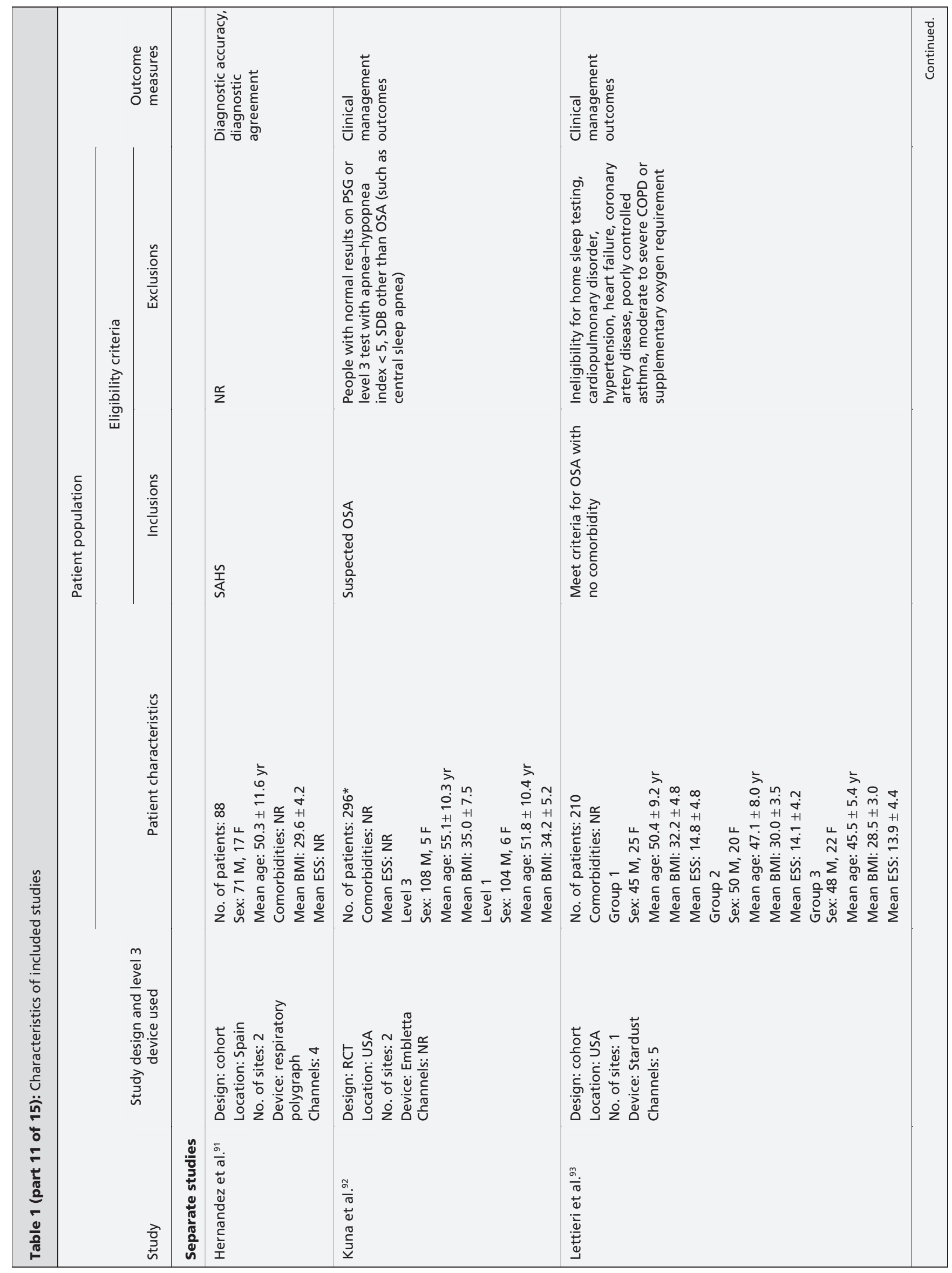




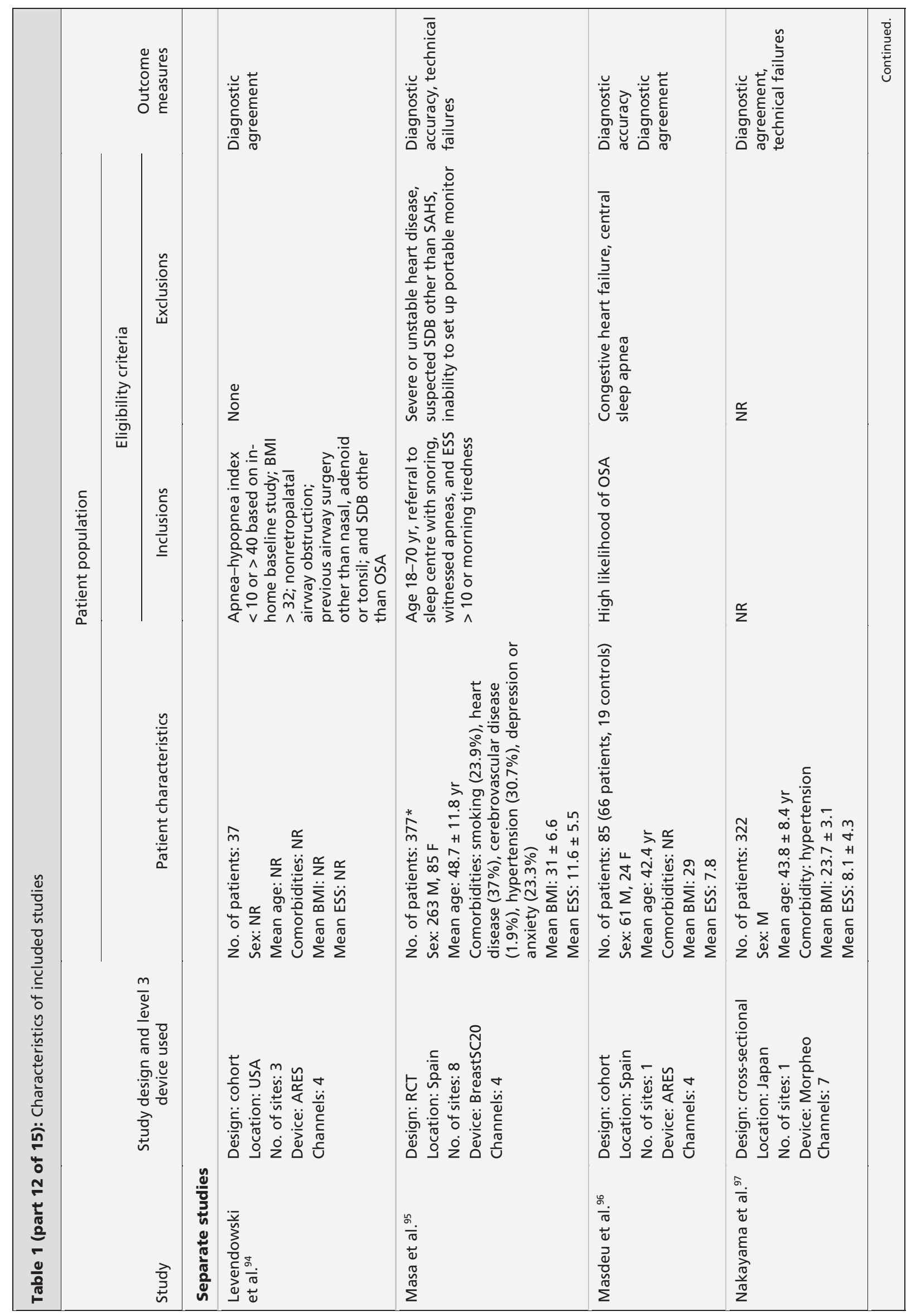




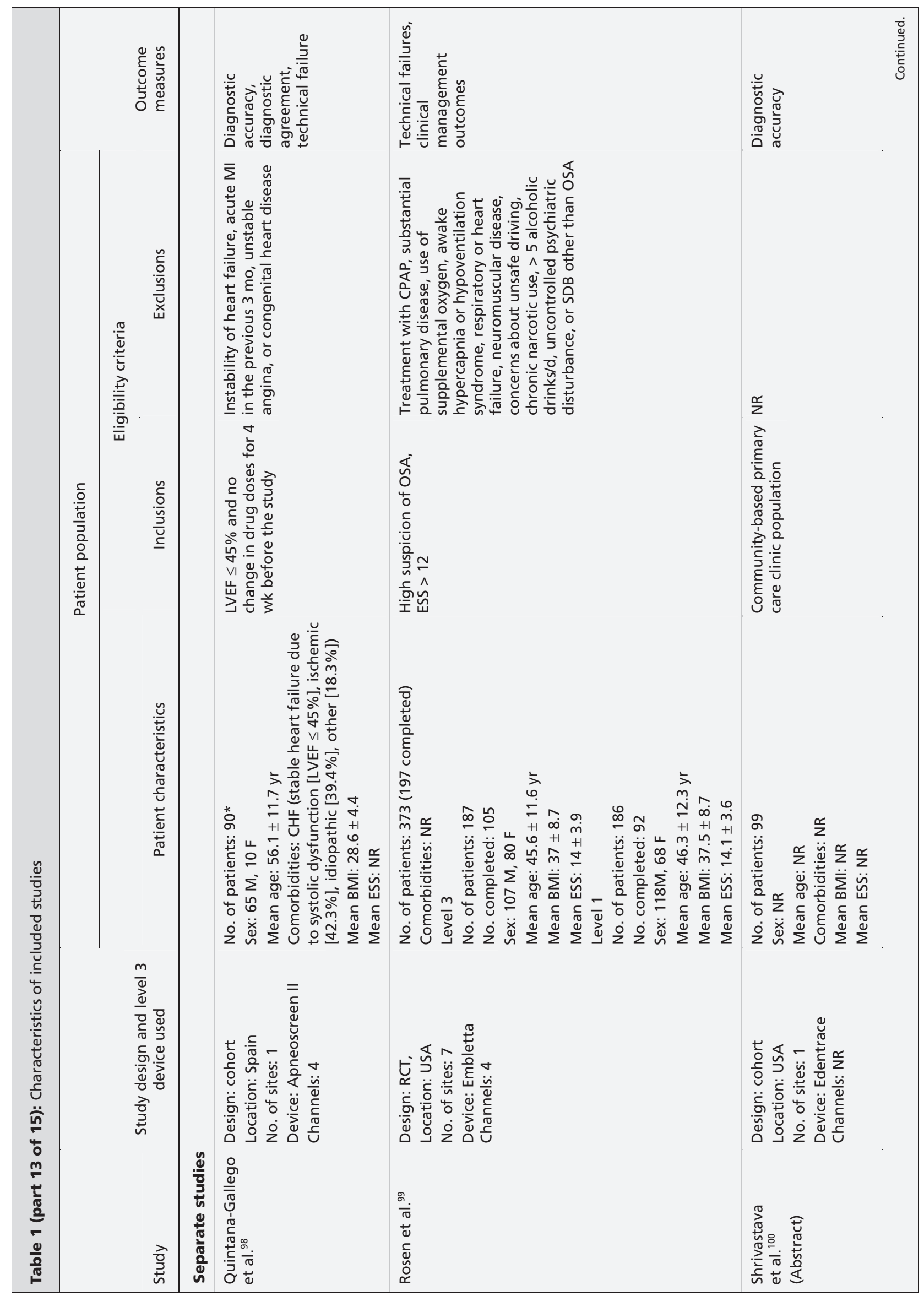




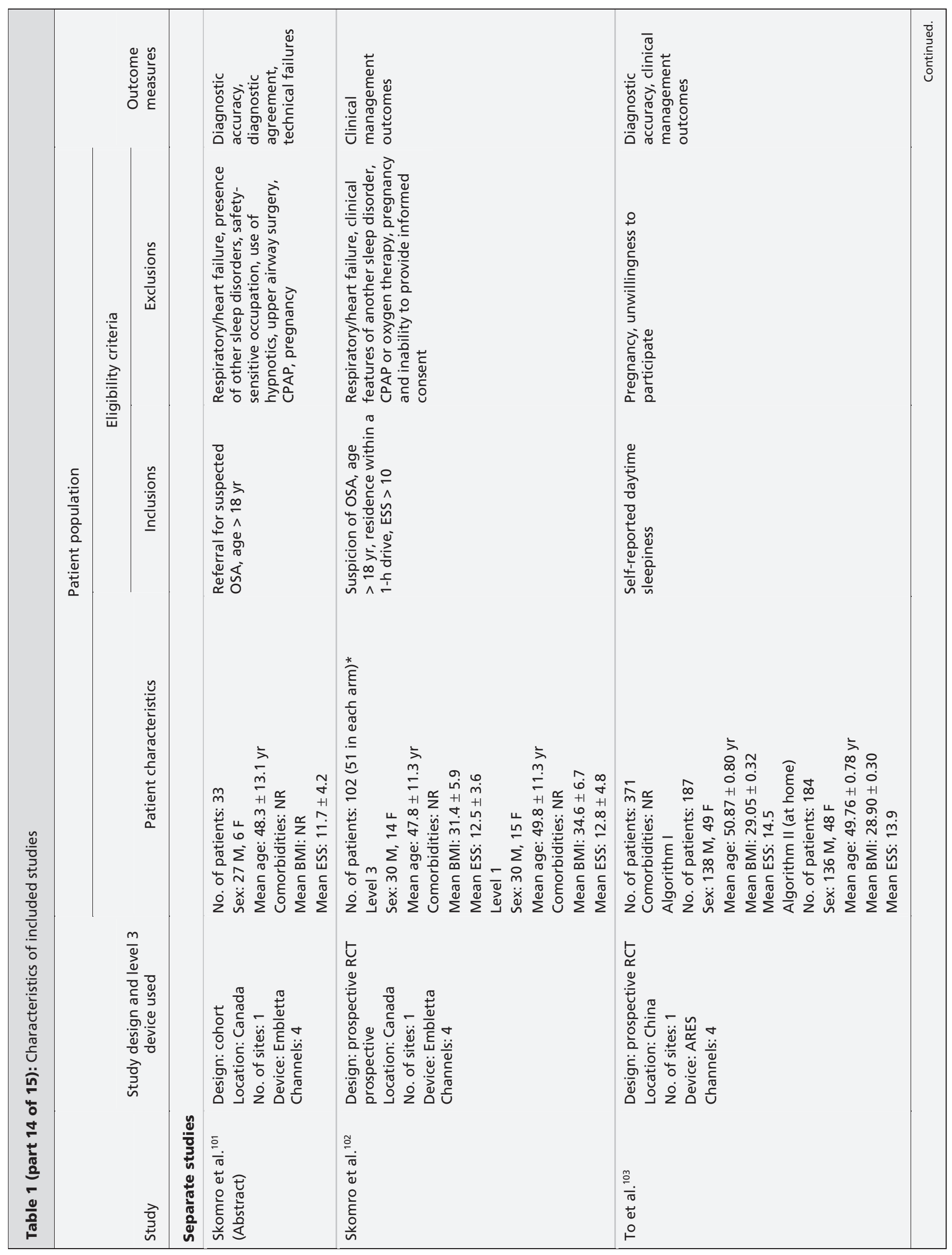




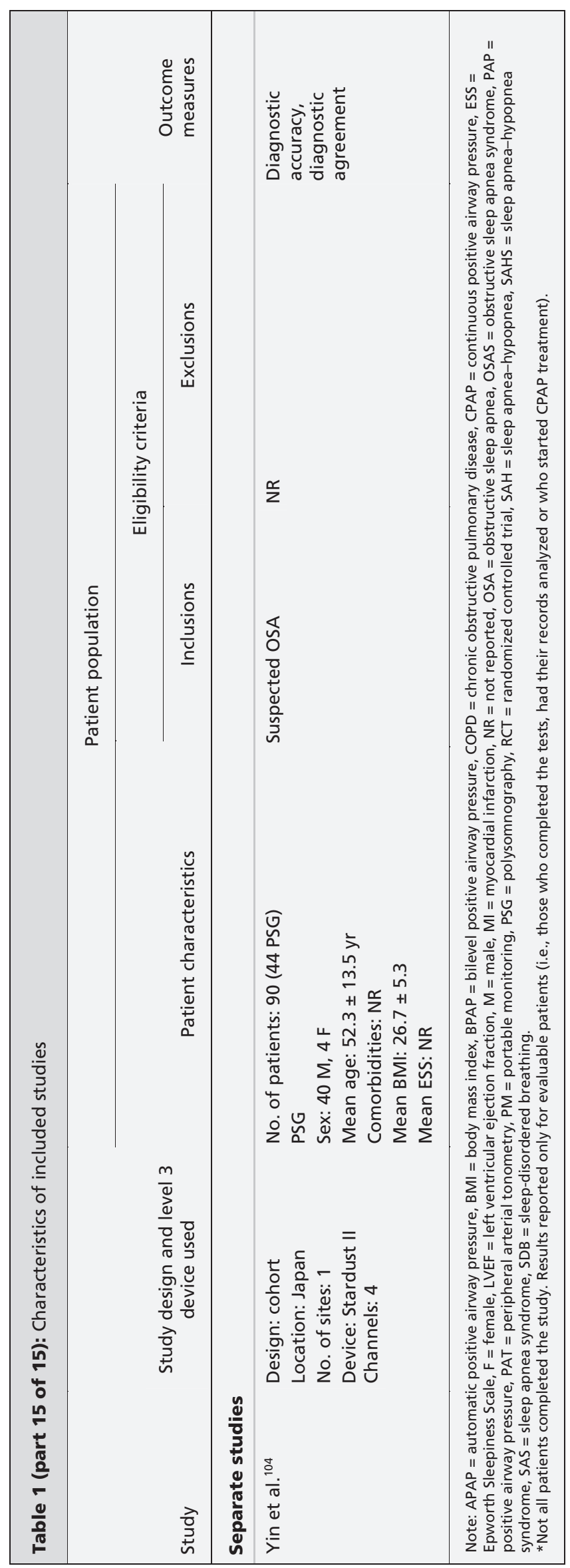


Table 2 (part 1 of 2): Quality appraisal of the included studies using the QUADAS-2 tool

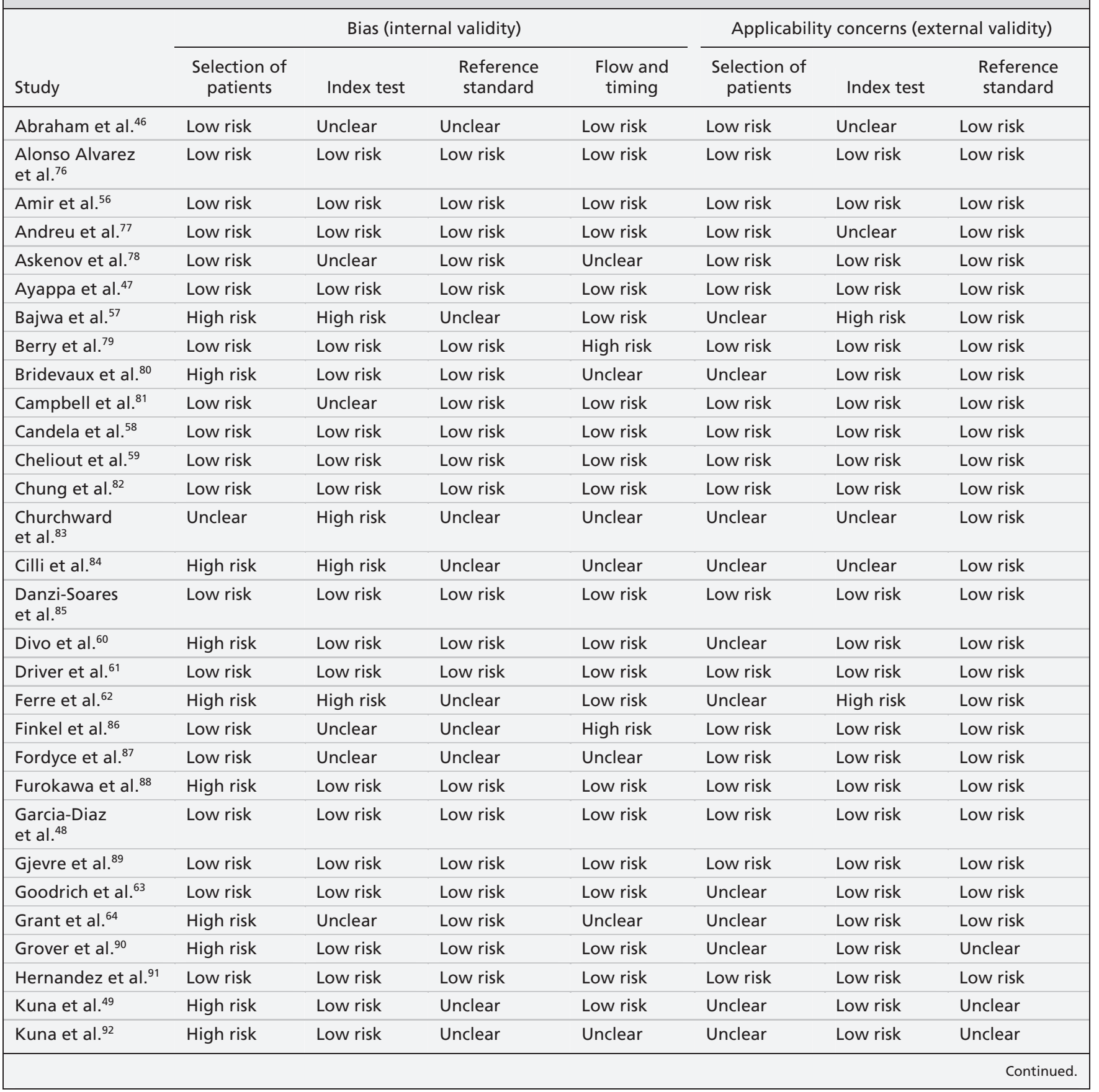


Table 2 (part 2 of 2): Quality appraisal of the included studies using the QUADAS-2 tool

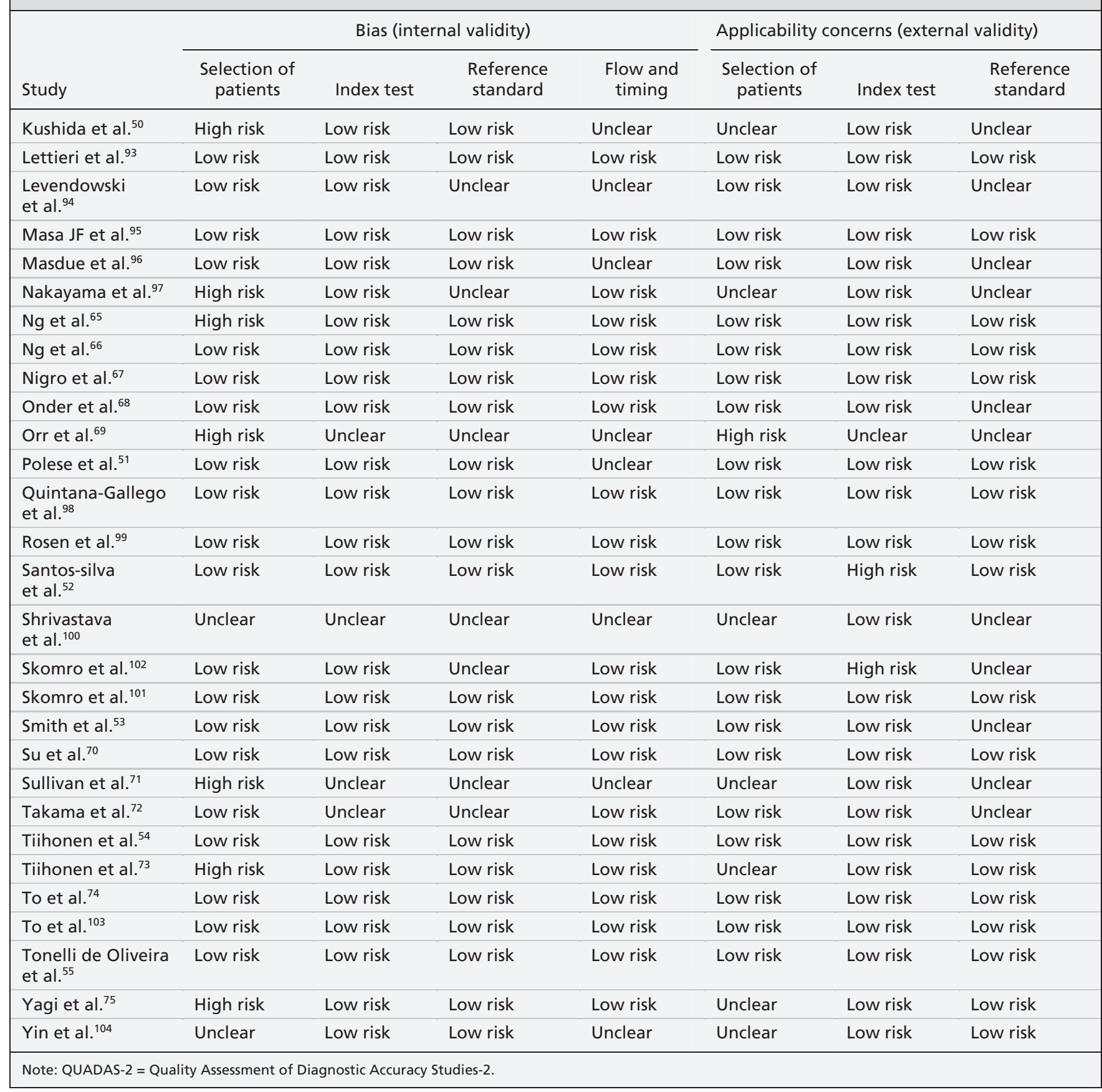




\begin{tabular}{|c|c|c|c|c|c|c|c|c|c|c|c|}
\hline 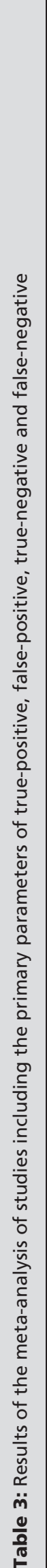 & 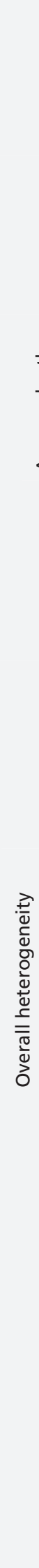 & 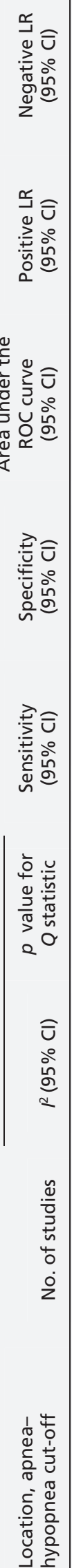 & 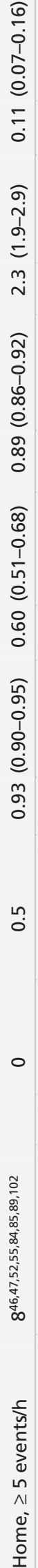 & 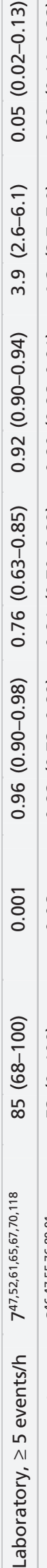 & 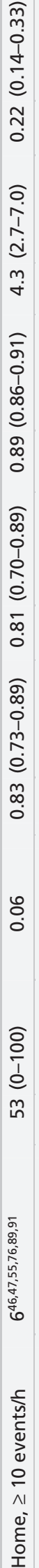 & 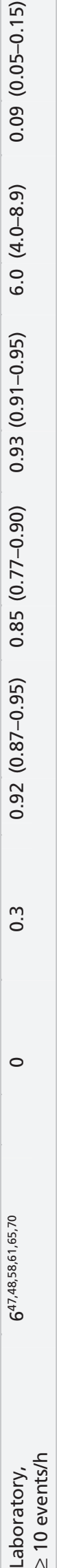 & 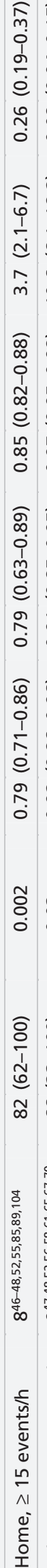 & 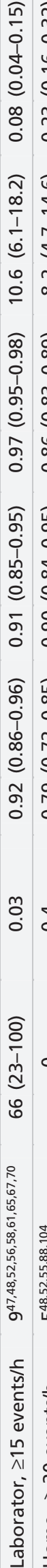 & 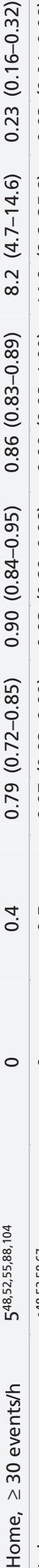 & 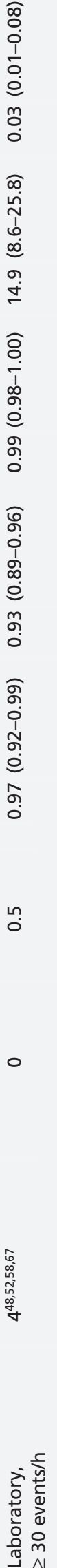 & 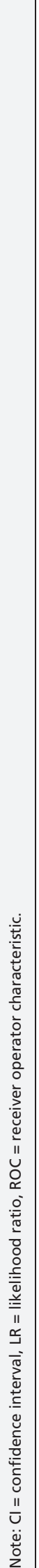 \\
\hline
\end{tabular}




\section{Sensitivity analysis}

When we removed the 3 studies that recruited only patients with comorbidities from the metaanalysis, the results of in-laboratory sleep testing remained unchanged, because the excluded studies had only been done at the patients' homes. Sensitivity in the at-home setting showed a slight improvement, ranging from $1 \%$ to $3 \%$ at all apnea-hypopnea index cut-offs, with the exception of 10 or more events per hour (where sensitivity decreased from $83 \%$ to $81 \%$ ). Specificity improved by $2 \%$ and $3 \%$ at cut-offs of 5 or more and 10 or more events per hour, respectively, but remained unchanged at cut-offs of 15 or more and 30 or more events per hour. The area under the ROC curve improved slightly (1\%) at all cutoffs other than 10 or more events per hour.

\section{Interpretation}

Level 3 portable devices scored well for sensitivity (the ability of a test to correctly identify those who have the disease), and specificity (the ability of a test to correctly identify those who do not have the disease), with a trade-off of increasing specificity and decreasing sensitivity as disease severity increased. The areas under the ROC curves (a measure that combines sensitivity and specificity to show the overall discriminatory power of the test, with a value of 1 indicating perfect discrimi-
A

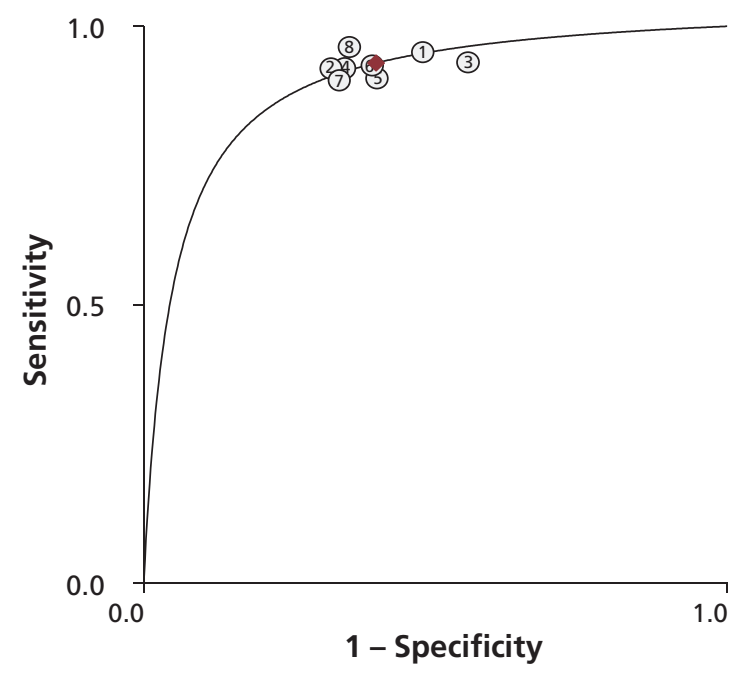

C

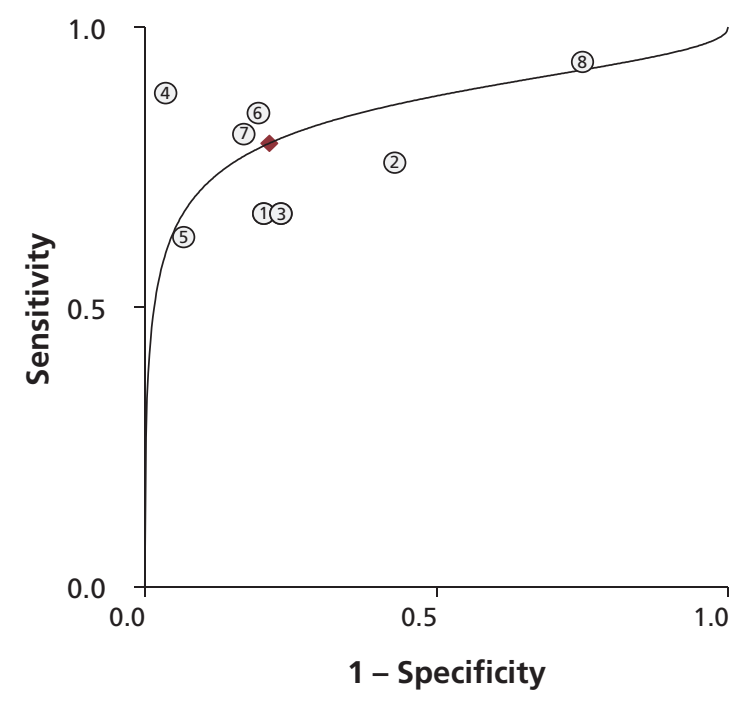

B

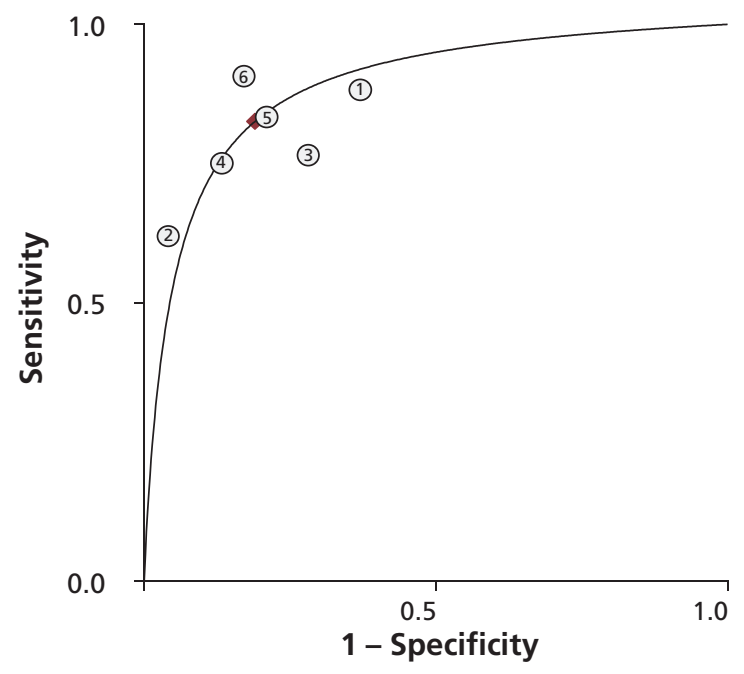

D

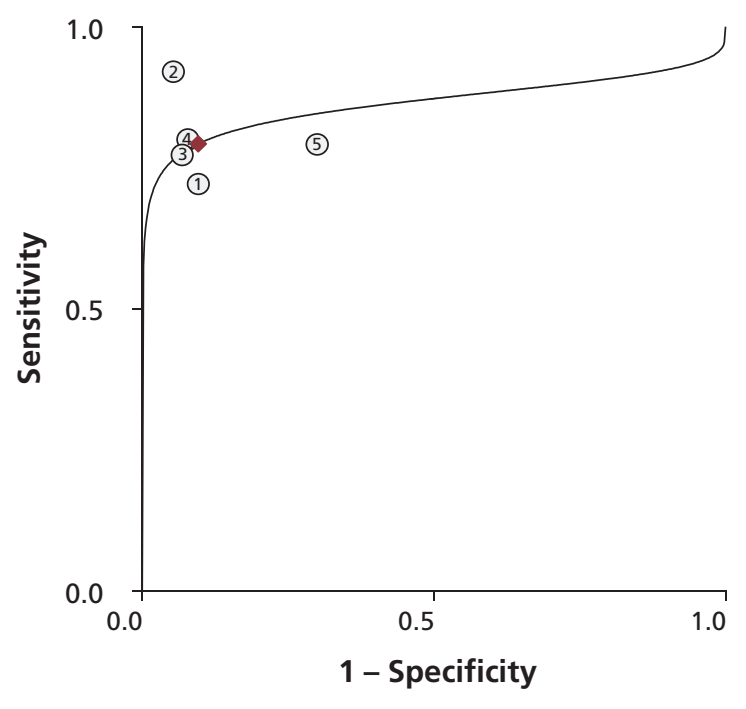

Figure 2: Summary receiver operating characteristic (ROC) curves comparing level 3 at-home sleep studies with level 1 in-laboratory studies. (A) ROC for apnea-hypopnea index $\geq 5$ events/h. (B) ROC for apnea-hypopnea index $\geq 10$ events/h. (C) ROC for apneahypopnea index $\geq 15$ events/h. (D) ROC for apnea-hypopnea index $\geq 30$ events/h. 
nation) confirmed the performance of level 3 devices. The performance of level 3 devices was better in the laboratory than at home - the devices had a high technical failure rate when testing was done at home. Bruyneel and colleagues reported similar rates in their study comparing level 1 inlaboratory to unattended level 1 at-home sleep studies (the latter is considered level 2 testing). The unattended level 1 studies had similar rates of technical failures, despite using full polysomnography equipment, suggesting the failures were because a sleep technician was not in attendance..$^{106}$

Despite the heterogeneity we saw at some apnea-hypopnea index cut-offs in our metaanalysis, the pooled estimates of diagnostic accuracy parameters appear reliable. We used a model that accounts for this heterogeneity ${ }^{107-110}$ despite the use of different level 3 devices, which each measured the same core parameters.

The studies included in this review were designed to evaluate diagnostic accuracy rather than identify subpopulations of patients who might benefit from each test. Most patients in these studies had uncomplicated obstructive sleep apnea without unstable comorbidities. The patients were typically referred from sleep or respiratory clinics where a comprehensive pretest evaluation had been completed, suggesting a high pretest probability of obstructive sleep apnea (e.g., symptoms such as snoring and day-

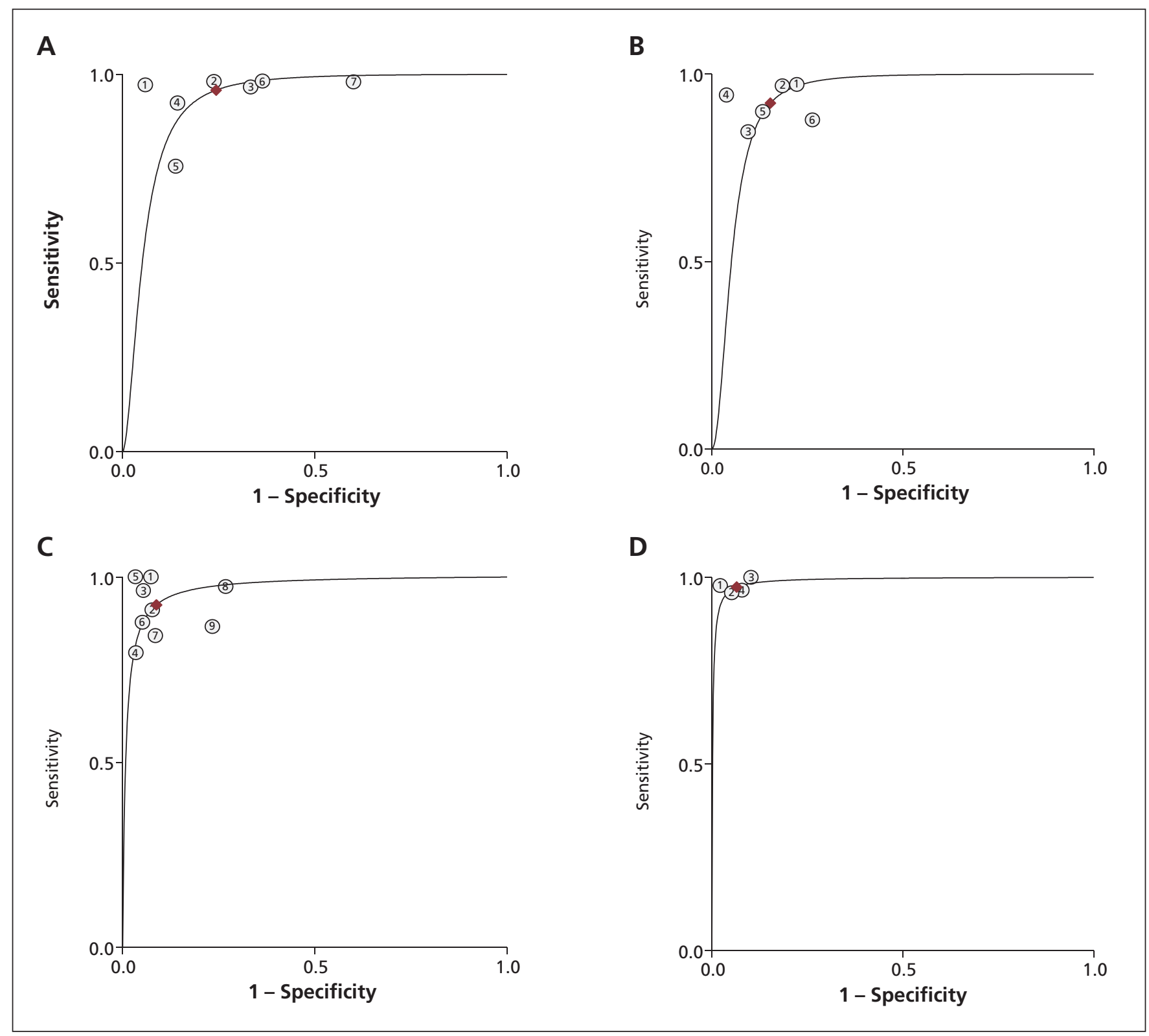

Figure 3: Summary receiver operating characteristic (ROC) curves comparing level 3 and level 1 in-laboratory sleep studies. (A) ROC for apnea-hypopnea index $\geq 5$ events/h. (B) ROC for apnea-hypopnea index $\geq 10$ events/h. (C) ROC for apnea-hypopnea index $\geq 15$ events/h. (D) ROC for apnea-hypopnea index $\geq 30$ events/h. 
time sleepiness). Family physicians play a key role in the diagnosis of sleep-disordered breathing. Reuveni and colleagues discussed the need for educational programs to increase awareness among family physicians of the signs of obstructive sleep apnea. ${ }^{111}$ Such programs will likely increase testing, optimize the use of diagnostic resources and expedite treatment. ${ }^{112-114}$

Our findings confirm those of previous reviews, health technology assessments and clinical practice guidelines based on earlier evidence of portable monitor use in the diagnosis of sleepdisordered breathing. ${ }^{25-27,31-39,115}$ These reviews concluded that level 3 devices are useful in the diagnosis of obstructive sleep apnea in patients with a high pretest likelihood of having moderate to severe forms of the condition. The American Academy of Sleep Medicine and Canadian Sleep Society/Canadian Thoracic Society guidelines recommend that portable sleep studies be provided under the direction of health professionals with accreditation in sleep medicine and as part of a comprehensive assessment. ${ }^{25-27}$ The US Centers for Medicare \& Medicaid Services has determined that portable devices (with a minimum of 3 channels) are acceptable for diagnosing obstructive sleep apnea in patients with clinical signs or symptoms suggestive of the condition. ${ }^{116}$

\section{Limitations}

We included only English-language studies in this review, therefore it is possible that relevant studies in other languages were excluded. In addition, none of the studies included patients with forms of sleep-disordered breathing other than obstructive sleep apnea, limiting the generalizability of the results to patients with other forms of sleep-disordered breathing.

\section{Conclusion}

Level 3 sleep studies are safe and convenient for diagnosing obstructive sleep apnea in patients with a high pretest probability of moderate to severe forms of the condition without substantial comorbidities. Level 1 polysomnography remains the cornerstone for the diagnosis in patients suspected of having comorbid sleep disorders, unstable medical conditions or complex sleep-disordered breathing. Further studies assessing the use of portable sleep studies in patients with conditions other than obstructive sleep apnea, and in patients with obstructive sleep apnea and comorbidities, are needed.

\section{References}

1. Young T, Palta M, Dempsey J, et al. Burden of sleep apnea: rationale, design, and major findings of the Wisconsin Sleep Cohort study. WMJ 2009;108:246-9.

2. Tregear S, Reston J, Schoelles K, et al. Obstructive sleep apnea and risk of motor vehicle crash: systematic review and metaanalysis. J Clin Sleep Med 2009;5:573-81.

3. Ellen RL, Marshall SC, Palayew M, et al. Systematic review of motor vehicle crash risk in persons with sleep apnea. J Clin Sleep Med 2006;2:193-200.

4. Gurubhagavatula I, Nkwuo JE, Maislin G, et al. Estimated cost of crashes in commercial drivers supports screening and treatment of obstructive sleep apnea. Accid Anal Prev 2008;40:104-15.

5. Mulgrew AT, Nasvadi G, Butt A, et al. Risk and severity of motor vehicle crashes in patients with obstructive sleep apnoea/hypopnoea. Thorax 2008;63:536-41.

6. AlGhanim N, Comondore VR, Fleetham J, et al. The economic impact of obstructive sleep apnea. Lung 2008;186:7-12.

7. Gander P, Scott G, Mihaere K, et al. Societal costs of obstructive sleep apnoea syndrome. N Z Med J 2010;123:13-23.

8. Somers VK, White DP, Amin R, et al. Sleep apnea and cardiovascular disease: an American Heart Association/American College of Cardiology Foundation Scientific Statement from the American Heart Association Council for High Blood Pressure Research Professional Education Committee, Council on Clinical Cardiology, Stroke Council, and Council on Cardiovascular Nursing. J Am Coll Cardiol 2008;52:686-717.

9. Ronksley PE, Tsai WH, Quan H, et al. Data enhancement for co-morbidity measurement among patients referred for sleep diagnostic testing: an observational study. BMC Med Res Methodol 2009;9:50.

10. Hensley M, Ray C. Sleep apnoea. Clin Evid (Online) $2007 \mathrm{Ju}$ 1;2007. pii: 2301

11. Young T. Rationale, design and findings from the Wisconsin Sleep Cohort Study: toward understanding the total societal burden of sleep disordered breathing. Sleep Med Clin 2009;4:37-46.

12. Seicean S, Strohl KP, Seicean A, et al. Sleep disordered breathing as a risk of cardiac events in subjects with diabetes mellitus and normal exercise echocardiographic findings. Am J Cardiol 2013;111:1214-20.

13. Tarasiuk A, Greenberg-Dotan S, Simon-Tuval T, et al. The effect of obstructive sleep apnea on morbidity and health care utilization of middle-aged and older adults. J Am Geriatr Soc 2008;56:247-54.

14. Jennum P, Kjellberg J. Health, social and economical consequences of sleep-disordered breathing: a controlled national study. Thorax 2011;66:560-6.

15. Kapur V, Blough DK, Sandblom RE, et al. The medical cost of undiagnosed sleep apnea. Sleep 1999;22:749-55.

16. Bahammam A. Delaive K, Ronald J, et al. Health care utilization in males with obstructive sleep apnea syndrome two years after diagnosis and treatment. Sleep 1999;22:740-7.

17. Banno K, Ramsey C, Walld R, et al. Expenditure on health care in obese women with and without sleep apnea. Sleep 2009;32: 247-52.

18. Strohl KP. Overview of obstructive sleep apnea in adults. Waltham (MA): UpToDate; 2013.

19. Epstein LJ, Kristo D, Strollo PJ Jr, et al. Clinical guideline for the evaluation, management and long-term care of obstructive sleep apnea in adults. J Clin Sleep Med 2009;5:263-76.

20. Sleep-related breathing disorders in adults: recommendations for syndrome definition and measurement techniques in clinical research. The Report of an American Academy of Sleep Medicine Task Force. Sleep 1999;22:667-89.

21. Akinnusi M, Saliba R, El-Solh AA. Emerging therapies for obstructive sleep apnea. Lung 2012;190:365-71.

22. What is the impact of sleep apnea on Canadians? Fast facts from the 2009 Canadian Community Health Survey — sleep apnea rapid response. Ottawa $(\mathrm{ON})$ : Public Health Agency of Canada; 2009.

23. Jennum P, Riha RL. Epidemiology of sleep apnoea/hypopnoea syndrome and sleep-disordered breathing. Eur Respir J 2009;33: 907-14.

24. Decramer M, Janssens W, Miravitlles M. Chronic obstructive pulmonary disease. Lancet 2012;379:1341-51.

25. Fleetham J, Ayas N, Bradley D, et al. Canadian Thoracic Society 2011 guideline update: diagnosis and treatment of sleep disordered breathing. Can Respir J 2011;18:25-47.

26. Collop NA, Anderson WM, Boehlecke B, et al. Clinical guidelines for the use of unattended portable monitors in the diagnosis of obstructive sleep apnea in adult patients. Portable Monitoring Task Force of the American Academy of Sleep Medicine. J Clin Sleep Med 2007;3:737-47.

27. Blackman A, McGregor C, Dales R, et al. Canadian Sleep Society/Canadian Thoracic Society position paper on the use of portable monitoring for the diagnosis of obstructive sleep apnea/hypopnea in adults. Can Respir J 2010;17:229-32.

28. Flemons WW, Douglas NJ, Kuna ST, et al. Access to diagnosis and treatment of patients with suspected sleep apnea. Am J Respir Crit Care Med 2004;169:668-72.

29. Mohsenin V. Portable monitoring for obstructive sleep apnea: 
the horse is out of the barn: avoiding pitfalls. Am J Med 2013; 126:e1-3

30. Collop N. Portable monitoring in obstructive sleep apnea in adults. Waltham (MA): UpToDate; 2012.

31. An assessment of sleep disordered breathing diagnosis using level I versus level III sleep studies. Final report. Edmonton (AB): Prepared for Alberta Health and Wellness by the Health Technology \& Policy Unit, School of Public Health, University of Alberta; 2010.

32. Ndegwa S, Clark M, Argaez C. Portable monitoring devices for diagnosis of obstructive sleep apnea at home: review of accuracy, cost effectiveness, guidelines, and coverage in Canada. Ottawa (ON): Canadian Agency for Drugs and Technologies in Health (CADTH); 2009.

33. Trikalinos TA, Lau J. Home diagnosis of obstructive sleep apnea-hypopnea syndrome. Rockville (MD): Agency for Healthcare Quality and Research (AHRQ); 2007.

34. Trikalinos TA, Lau J. Obstructive sleep apnea-hypopnea syndrome: modeling different diagnostic strategies. Rockville (MD): Agency for Healthcare Research and Quality (AHRQ); 2007.

35. Diagnosis and treatment of obstructive sleep apnea [Health Care Guideline]. 6th ed. Bloomington (MN): Institute for Clinical Systems Improvement; 2008.

36. Balk EM, Moorthy D, Obadan NO, et al. Diagnosis and treatment of obstructive sleep apnea in adults [AHRQ comparative effectiveness reviews]. Rockville (MD): Agency for Healthcare Research and Quality (AHRQ); 2011.

37. Ghegan MD, Angelos PC, Stonebraker AC, et al. Laboratory versus portable sleep studies: a meta-analysis. Laryngoscope 2006; 116:859-64.

38. Polysomnography in patients with obstructive sleep apnea: an evidence-based analysis. Toronto $(\mathrm{ON})$ : Medical Advisory Secretariat, Ontario Ministry of Health and Long-Term Care; 2006.

39. Gleitsmann K, Kriz H, Thielke A, et al. Sleep apnea diagnosis and treatment in adults. Final evidence report. Portland (OR): Center for Evidence-based Policy, Oregon Health and Science University for the Washington State Health Care Authority; 2012.

40. Flemons WW, Littner MR, Rowley JA, et al. Home diagnosis of sleep apnea: a systematic review of the literature. An evidence review cosponsored by the American Academy of Sleep Medicine, the American College of Chest Physicians, and the American Thoracic Society. Chest 2003;124:1543-79.

41. Whiting PF, Rutjes AW, Westwood ME, et al. QUADAS-2: a revised tool for the quality assessment of diagnostic accuracy studies. Ann Intern Med 2011;155:529-36.

42. Whiting P, Rutjes AW, Reitsma JB, et al. The development of QUADAS: a tool for the quality assessment of studies of diagnostic accuracy included in systematic reviews. BMC Med Res Methodol 2003;3:25.

43. Huedo-Medina T, Sanchez-Meca J, Marin-Martinez F, et al. Assessing heterogeneity in meta-analysis: $Q$ statistic or $I 2$ index? Storrs (CT): Center for Health, Intervention, and Prevention (CHIP); 2006.

44. Higgins JP. Heterogeneity in meta-analysis should be expected and appropriately quantified. Int J Epidemiol 2008;37:1158-60.

45. Fletcher J. What is heterogeneity and is it important? BMJ 2007; 334:94-6.

46. Abraham WT, Trupp RJ, Phillilps B, et al. Validation and clinical utility of a simple in-home testing tool for sleep-disordered breathing and arrhythmias in heart failure: results of the Sleep Events, Arrhythmias, and Respiratory Analysis in Congestive Heart Failure (SEARCH) study. Congest Heart Fail 2006;12:241-7.

47. Ayappa I, Norman RG, Seelall V, et al. Validation of a selfapplied unattended monitor for sleep disordered breathing. $J$ Clin Sleep Med 2008;4:26-37.

48. García-Díaz E, Quintana-Gallego E, Ruiz A, et al. Respiratory polygraphy with actigraphy in the diagnosis of sleep apneahypopnea syndrome. Chest 2007;131:725-32.

49. Kuna ST, Seeger T, Brendel M. Intra-subject comparison of polysomnography and a type 3 portable monitor [abstract]. Sleep 2005;28(Suppl):A324 (abstract no. 0956).

50. Kushida CA, Cardell C, Black S, et al. Comparison of a new type 3 portable monitor for OSA detection vs. in-lab polysomnography [abstract]. Sleep 2009;32(Suppl):A385 (abstract no. 1178).

51. Polese JF, Santos SR, Sartori DE, et al. Validation of a portable monitoring systemfor the diagnosis of obstructive sleep apnea in elderly patients [abstract]. Sleep Medicine 2009;10(Suppl 2):S22 (abstract no. 078)

52. Santos-Silva R, Sartori DE, Truksinas V, et al. Validation of a portable monitoring system for the diagnosis of obstructive sleep apnea syndrome. Sleep 2009;32:629-36.

53. Smith LA, Chong DW, Vennelle M, et al. Diagnosis of sleepdisordered breathing in patients with chronic heart failure: evaluation of a portable limited sleep study system. J Sleep Res 2007; $16: 428-35$.
54. Tiihonen P, Paakkonen A, Mervaala E, et al. Design, construction and evaluation of an ambulatory device for screening of sleep apnea. Med Biol Eng Comput 2009;47:59-66.

55. Tonelli de Oliveira AC, Martinez D, Vasconcelos LF, et al. Diagnosis of obstructive sleep apnea syndrome and its outcomes with home portable monitoring. Chest 2009;135:330-6.

56. Amir O, Barak-Shinar D, Amos Y, et al. An automated sleep-analysis system operated through a standard hospital monitor. J Clin Sleep Med 2010;6:59-63.

57. Bajwa I, Grover S, Clawson T, Cady M. Validity of respiratory events collected from a portable monitoring device [abstract]. Sleep 2009;32(Suppl):A376 (abstract no. 1150).

58. Candela A, Hernandez L, Asensio S, et al. Validation of a respiratory polygraphy system in the diagnosis of sleep apnea syndrome. Arch Bronconeumol 2005;41:71-7.

59. Cheliout-Heraut F, Senny F, Djouadi F, et al. Obstructive sleep apnoea syndrome: comparison between polysomnography and portable sleep monitoring based on jaw recordings. Neurophysiol Clin 2011;41:191-8

60. Morales Divo C., Selivanova O, Mewes T, et al. Polysomnography and ApneaGraph in patients with sleep-related breathing disorders. ORL J Otorhinolaryngol Relat Spec 2009;71:27-31.

61. Driver HS, Pereira EJ, Bjerring K, et al. Validation of the MediByte $(\mathrm{R})$ type 3 portable monitor compared with polysomnography for screening of obstructive sleep apnea. Can Respir J 2011; 18:137-43.

62. Ferre A, Grau M, Jurado M, et al. Evaluation of a new simplified polysomnography system for the diagnosis of sleep disordered breathing [abstract]. J Sleep Res 2008;17(Suppl 1):234 (abstract no. P441).

63. Goodrich S, Orr WC. An investigation of the validity of the Lifeshirt in comparison to standard polysomnography in the detection of obstructive sleep apnea. Sleep Med 2009;10:118-22.

64. Grant B. Diagnostic accuracy of home sleep studies for sleep apnea [abstract]. Sleep 2009;32(Suppl):A232 (abstract no. 713).

65. Ng SS, Chan TO, To KW, et al. Validation of Embletta portable diagnostic system for identifying patients with suspected obstructive sleep apnoea syndrome (OSAS). Respirology 2010;15:336-42.

66. Ng SS, Chan TO, To KW, et al. Validation of a portable recording device (ApneaLink) for identifying patients with suspected obstructive sleep apnoea syndrome. Intern Med J 2009;39:757-62.

67. Nigro CA, Serrano F, Aimaretti S, et al. Utility of ApneaLink for the diagnosis of sleep apnea-hypopnea syndrome. Medicina (B Aires) 2010;70:53-9.

68. Onder NS, Akpinar ME, Yigit O, et al. Watch peripheral arterial tonometry in the diagnosis of obstructive sleep apnea: influence of aging. Laryngoscope 2012;122:1409-14

69. Orr WC, Goodrich S. An investigation of the accuracy of the Lifeshirt in comparison to standard polysomnography [abstract]. Sleep 2006;29(Suppl):A348 (abstract no. 1020).

70. Su S, Baroody FM, Kohrman M, et al. A comparison of polysomnography and a portable home sleep study in the diagnosis of obstructive sleep apnea syndrome. Otolaryngol Head Neck Surg 2004;131:844-50.

71. Sullivan GE, Morehouse R, Savoy A. Comparison of synchronized level 1 and level 3 sleep studies [abstract]. Vigilance 2009; 19(Suppl) (abstract no. P074).

72. Takama N, Kurabayashi M. Effectiveness of a portable device and the need for treatment of mild-to-moderate obstructive sleep-disordered breathing in patients with cardiovascular disease. J Cardiol 2010;56:73-8.

73. Tiihonen P, Hukkanen T, Tuomilehto H, et al. Evaluation of a novel ambulatory device for screening of sleep apnea. Telemed J E Health 2009;15:283-9.

74. To KW, Chan WC, Chan TO, et al. Validation study of a portable monitoring device for identifying OSA in a symptomatic patient population. Respirology 2009;14:270-5.

75. Yagi H, Nakata S, Tsuge H, et al. Significance of a screening device (Apnomonitor 5) for sleep apnea syndrome. Auris Nasus Larynx 2009;36:176-80

76. Alonso Alvarez ML, Santos JT, Guevara JC, et al. Reliability of home respiratory polygraphy for the diagnosis of sleep apneahypopnea syndrome: analysis of costs. Arch Bronconeumol 2008; 44:22-8.

77. Andreu AL, Chiner E, Sancho-Chust JN, et al. Effect of an ambulatory diagnostic and treatment programme in patients with sleep apnoea. Eur Respir J 2012;39:305-12.

78. Aksenov IV, Foster C, Berry RB. Management of obstructive sleep apnea: portable monitoring for diagnosis followed by treatment with auto-adjusting positive airway pressure [abstract]. Sleep 2009;32(Suppl):A183 (abstract no. 0557).

79. Berry RB, Hill G, Thompson L, et al. Portable monitoring and autotitration versus polysomnography for the diagnosis and treatment of sleep apnea. Sleep 2008;31:1423-31. 
80. Bridevaux PO, Fitting JW, Fellrath JM, et al. Inter-observer agreement on apnoea hypopnoea index using portable monitoring of respiratory parameters. Swiss Med Wkly 2007;137:602-7.

81. Campbell AJ, Neill AM. Home set-up polysomnography in the assessment of suspected obstructive sleep apnea. J Sleep Res 2011; 20:207-13.

82. Chung F, Liao P, Sun Y, et al. Perioperative practical experiences in using a level 2 portable polysomnography. Sleep Breath 2011; $15: 367-75$

83. Churchward TJ, O’Donoghue F, Rochford P, et al. Diagnostic accuracy and cost effectiveness of home-based PSG in OSA [abstract]. Sleep Biol Rhythms 2006;4(Suppl):A11 (abstract no. $0-11)$.

84. Cilli A, Erogullari I, Turhan M, et al. Comparison of Embletta portable device versus Embla for diagnosing the obstructive sleep apnea [abstract]. J Sleep Res 2006;15(Suppl 1):152.

85. Danzi-Soares NJ, Genta PR, Nerbass FB, et al. Obstructive sleep apnea is common among patients referred for coronary artery bypass grafting and can be diagnosed by portable monitoring. Coron Artery Dis 2012;23:31-8

86. Finkel KJ, Searleman AC, Tymkew H, et al. Prevalence of undiagnosed obstructive sleep apnea among adult surgical patients in an academic medical center. Sleep Med 2009;10:753-8.

87. Fordyce L, Samuels CH, Oram C, et al. A retrospective, observational study showing patients with a normal level III sleep study and normal OSA pretest probability factors may still require additional investigations [abstract]. Vigilance 2009; 19(Suppl) (abstract no. P075).

88. Furukawa T, Suzuki M, Funatogawa I, et al. Screening method for severe sleep-disordered breathing in hypertensive patients without daytime sleepiness. J Cardiol 2009;53:79-85.

89. Gjevre JA, Taylor-Gjevre RM, Skomro R, et al. Comparison of polysomnographic and portable home monitoring assessments of obstructive sleep apnea in Saskatchewan women. Can Respir J 2011;18:271-4.

90. Grover S, Cady M. A user-friendly device for home monitoring of sleep disorders [abstract]. Sleep 2009;32(Suppl):A371 (abstract no. 1136).

91. Hernández L, Torrella M, Roger N, et al. Management of sleep apnea: concordance between nonreference and reference centers. Chest 2007; 132:1853-7.

92. Kuna ST, Gurubhagavatula I, Maislin G, et al. Noninferiority of functional outcome in ambulatory management of obstructive sleep apnea. Am J Respir Crit Care Med 2011;183:1238-44

93. Lettieri CF, Lettieri CJ, Carter K. Does home sleep testing impair continuous positive airway pressure adherence in patients with obstructive sleep apnea? Chest 2011;139:849-54.

94. Levendowski D, Steward D, Woodson BT, et al. The impact of obstructive sleep apnea variability measured in-lab versus inhome on sample size calculations. Int Arch Med 2009;2:2

95. Masa JF, Corral J, Pereira R, et al. Therapeutic decision-making for sleep apnea and hypopnea syndrome using home respiratory polygraphy: a large multicentric study. Am J Respir Crit Care Med 2011;184:964-71.

96. Masdeu MJ, Ayappa I, Hwang D, et al. Impact of clinical assessment on use of data from unattended limited monitoring as opposed to full-in lab PSG in sleep disordered breathing. J Clin Sleep Med 2010;6:51-8.

97. Nakayama-Ashida Y, Takegami M, Chin K, et al. Sleep-disordered breathing in the usual lifestyle setting as detected with home monitoring in a population of working men in Japan. Sleep 2008;31:419-25.

98. Quintana-Gallego E, Villa-Gil M, Carmona-Bernal C, et al Home respiratory polygraphy for diagnosis of sleep-disordered breathing in heart failure. Eur Respir J 2004;24:443-8.

99. Rosen CL, Auckley D, Benca R, et al. A multisite randomized trial of portable sleep studies and positive airway pressure autotitration versus laboratory-based polysomnography for the diagnosis and treatment of obstructive sleep apnea: the HomePAP Study. Sleep 2012;35:757-67.

100. Shrivastava D, Aurora NR, Gathoo M, et al. Home diagnostic portable monitoring: an effective screening tool in a communitybased primary care population [abstract]. Sleep 2006;29(Suppl): A192 (abstract no. 565).

101. Skomro R, Cotton D, Gjevre J, et al. Diagnosis of obstructive sleep apnea using unattended level III monitoring [abstract]. Sleep 2005;28(Suppl):A164 (abstract no. 0483).

102. Skomro RP, Gjevre J, Reid J, et al. Outcomes of home-based diagnosis and treatment of obstructive sleep apnea. Chest 2010; 138:257-63.

103. To KW, Chan WC, Chan TO, et al. Comparison of empirica continuous positive airway pressure (CPAP) treatment versus initial portable sleep monitoring followed by CPAP treatment for patients with suspected obstructive sleep apnoea. Intern Med J 2012;42:e107-14.

104. Yin M, Miyazaki S, Ishikawa K. Evaluation of type 3 portable monitoring in unattended home setting for suspected sleep apnea: factors that may affect its accuracy. Otolaryngol Head Neck Surg 2006;134:204-9.

105. Higgins JP, Thompson SG, Deeks JJ, et al. Measuring inconsistency in meta-analyses. BMJ 2003;327:557-60.

106. Bruyneel M, Sanida C, Art G, et al. Sleep efficiency during sleep studies: results of a prospective study comparing home-based and in-hospital polysomnography. J Sleep Res 2011;20(1 Part II):201-6.

107. Chu H, Guo H, Zhou Y. Bivariate random effects meta-analysis of diagnostic studies using generalized linear mixed models. Med Decis Making 2010;30:499-508.

108. Arends LR, Hamza TH, van Houwelingen JC, et al. Bivariate random effects meta-analysis of ROC curves. Med Decis Making 2008;28:621-38

109. Hamza TH, van Houwelingen HC, Stijnen T. The binomial distribution of meta-analysis was preferred to model within-study variability. J Clin Epidemiol 2008;61:41-51.

110. Riley RD, Abrams KR, Sutton AJ, et al. Bivariate random-effects meta-analysis and the estimation of between-study correlation. BMC Med Res Methodol 2007;7:3.

111. Reuveni H, Tarasiuk A, Wainstock T, et al. Awareness level of obstructive sleep apnea syndrome during routine unstructured interviews of a standardized patient by primary care physicians. Sleep 2004;27:1518-25.

112. Skjodt NM. Approach to outpatient management of adult sleep apnea. Can Fam Physician 2008;54:1408-12.

113. Culpepper L, Roth T. Recognizing and managing obstructive sleep apnea in primary care. Prim Care Companion J Clin Psychiatry 2009; 11:330-8

114. Ball EM, Simon RD Jr, Tall AA, et al. Diagnosis and treatment of sleep apnea within the community. The Walla Walla Project. Arch Intern Med 1997;157:419-24.

115. Tice JA. Portable devices used for home testing in obstructive sleep apnea. San Francisco (CA): California Technology Assessment Forum (CTAF); 2009.

116. Centers for Medicare \& Medicaid Services (CMS). Decision memo for sleep testing for obstructive sleep apnea (OSA) (CAG-00405N). Baltimore (MD): US Center for Medicare \& Medicaid Services (CMS); 2009.

Affiliations: Health Technology and Policy Unit, School of Public Health (El Shayeb, Topfer, Stafinski, Menon); Sleep Medicine Program (Pawluk), Department of Psychiatry, University of Alberta, Edmonton, Alta.

Contributors: Mohamed El Shayeb selected the studies, extracted the data, conducted the meta-analysis, analyzed the results and drafted the manuscript. Leigh-Ann Topfer conducted the literature search, and edited and revised the manuscript. Tania Stafinski helped conceive the design of the review, extracted the data, and edited and revised the manuscript. Lawrence Pawluk edited and revised the manuscript. Devidas Menon helped conceive the design of the review, extracted the data, and edited and reviewed the manuscript. All of the authors approved the final version submitted for publication.

Funding: Production of this work has been made possible by a financial contribution from Alberta Health and under the auspices of the Alberta Health Technologies Decision Process: the Alberta Model for Health Technology Assessment and Policy Analysis. The views expressed herein do not necessarily represent the official policy of Alberta Health. The study sponsor had no role in the design of the study, the collection, analysis or interpretation of data, the writing of the report, or the decision to submit the article for publication.

Acknowledgments: The authors thank Dr. Babak Bohlouli, University of Alberta, Department of Medicine, for his help with screening, reviewing and abstracting the data; Ms. Sarah Ndegwa for her help with reviewing and abstracting data; and Dr. Dominic Carney for his clinical advice throughout the project. 